\title{
Naming times and standardized norms for the Italian PD/DPSS set of 266 pictures: Direct comparisons with American, English, French, and Spanish published databases
}

\author{
ROBERTO DELLACQUA, LORELLA LOTTO, and REMO JOB \\ University of Padua, Padua, Italy
}

\begin{abstract}
The present study provides Italian normative measures for 266 line drawings belonging to the new set of pictures developed by Lotto, Dell'Acqua, and Job (in press). The pictures have been standardized on the following measures: number of letters, number of syllables, name frequency, within-category typicality, familiarity, age of acquisition, name agreement, and naming time. In addition to providing the measures, the present study focuses on indirect and direct comparisons (i.e., correlations) of the present norms with databases provided by comparable studies in Italian (in which normative data were collected with Snodgrass \& Vanderwart's set of pictures; Nisi, Longoni, \& Snodgrass, 2000), in British English (Barry, Morrison, \& Ellis, 1997), in American English (Snodgrass \& Vanderwart, 1980; Snodgrass \& Yuditsky, 1996), in French (Alario \& Ferrand, 1999), and in Spanish (Sanfeliu \& Fernandez, 1996).
\end{abstract}

It is unquestionable that the standardization of pictorial stimuli, such as that carried out in their seminal work by Snodgrass and Vanderwart (1980), had a positive effect on studies of object processing. Such stimuli have been used for research purposes in several fields of experimental psychology, with the obvious benefit of being readily available for selection according to the number of object characteristics that were obtained following their validation for an American sample. This standardized set of pictorial stimuli has been used in experiments with adults that focused on the difference in speed between reading words and naming pictures (e.g., Lotto, Rumiati, \& Job, 1996; Snodgrass \& McCullough, 1986; Vanderwart, 1984) and in perceptual identification and recognition experiments (e.g., Snodgrass, 1984; Snodgrass \& Corwin, 1988; Snodgrass \& Poster, 1992). In priming experiments, these stimuli have also been modified in order to study the effect of the prior exposure of fragmented pictures (e.g., Feenan \& Snodgrass, 1990; Snodgrass \& Feenan, 1992) or fragmented words (Snodgrass \& Poster, 1992) on processing of subsequent stimuli. Furthermore, in order to adapt the material to populations of different ages, the same set of stimuli has been

This work was supported by a START-UP grant (FFMA, 1998) to the authors. The authors are grateful to Anna Conti, Massimo Girelli, Stefania Marcellino, and Daniele Gasparini for help in collecting the data for the present study. The authors are indebted to Pierre Jolicœur, Judith Kroll, and Gay Snodgrass for useful comments on an earlier version of this paper and to Eraldo Nicotra and Massimiliano Pastore for statistical advice. Correspondence concerning this article should be addressed to R. Dell'Acqua, Dipartimento di Psicologia dello Sviluppo e della Socializzazione, 8, Via Venezia, 35131 Padova, Italy (e-mail: dellacqu@ psy.unipd.it). standardized for 5- to 6-year-old American children (Berman, Friedman, Hamberger, \& Snodgrass, 1989), and for 8- to 10-year-old American children (Cycowicz, Friedman, Rothstein, \& Snodgrass, 1997).

The widespread need for standardized pictorial material has recently motivated a series of studies in which normative data have been collected in different linguistic contexts, using Snodgrass and Vanderwart's (1980) set of pictures. This has been the case for British English (Barry, Morrison, \& Ellis, 1997), French (Alario \& Ferrand, 1999), Spanish (Sanfeliu \& Fernandez, 1996), Dutch (Martein, 1995), and Italian (Nisi, Longoni, \& Snodgrass, 2000). More or less generally across these studies, the rated object dimensions concerned the familiarity of the concepts represented by the pictures, the codability of the stimuli, such as the agreement on the names or on the images elicited by the pictures, the complexity of the visual structure of the pictures, and the age at which the concepts represented by the pictures were first processed and/or coded into memory. In two previous studies, measures of the time it took to name the pictures were also obtained (Barry et al., 1997; Snodgrass \& Yuditsky, 1996).

The scope of the present work is twofold. First, this work provides norms for a set of 266 pictures standardized for an Italian sample. We deviate from the commonly adopted procedure of using Snodgrass and Vanderwart's (1980) pictures. Instead, we presented, to a sample of Italian subjects $(N=178)$, a new set of pictures (Lotto, Dell'Acqua, \& Job, in press) that were extracted from sources other than previously published databases (i.e., adapted from dictionaries and books). These pictures are available in PCX bitmapped format (downloadable both as a zipped archive and as single items; http://olpss.psy. unipol.it/psychdata.htm). Furthermore, in order to invite 
researchers operating in different linguistic communities to use the present set of pictures, we provide both indirect and direct comparisons between the present normative data and those from previous studies that have used Snodgrass and Vanderwart's set of pictures for standardization purposes. In doing this, we propose a method by which to estimate the relative influence of cultural factors (e.g., linguistic factors and/or those modulated by the different cultural contexts) and visual factors (i.e., factors modulated by the visual dissimilarity among our and Snodgrass \& Vanderwart's pictures) on the distribution of the values reported across the studies that we examine.

\section{METHOD}

\section{Subjects}

A total of 178 students at the University of Padova volunteered to participate in this study. The age of the subjects ranged from 20 to 30 years. All the subjects had normal or corrected-to-normal vision. All the subjects in the naming experiment had normal hearing.

\section{Material}

A set of 266 black line drawings of real objects was generated for the present study. Some of the line drawings were created anew, and some were adapted from illustrations in dictionaries and books. The objects belonged to 13 distinct semantic categories (i.e., birds, buildings, clothes, flowers, furniture, fruits, housewares, mammals, musical instruments, receptacles, vegetables, vehicles, and weapons). An additional ad hoc category (i.e., mixed) was created by including objects belonging to different semantic categories for which only a few exemplars were available. The number of objects in each category varied from 11 to 32 . A file format version of each picture was obtained by importing picture hard copies on a computer via scanner. When displayed on the monitor of the computer (background luminance, $28 \mathrm{~cd} / \mathrm{m}^{2}$ ) in the naming experiment, each picture (about $25 \mathrm{~cd} / \mathrm{m}^{2}$ ) could be inscribed in a square with a side of less than $5^{\circ}$ of visual angle, at a viewing distance of about $60 \mathrm{~cm}$. For the rating procedure, the set of 266 picture hard copies was divided into two sublists, with the constraint that all the elements of a given semantic category were grouped in one sublist. This constraint did not apply to the pictures in the mixed category. For each sublist, a booklet was created in which each picture was reported in the center of a separate sheet, together with the name of the picture semantic category (above) and an $n$-point scale (see below), with $n$ depending on the rated dimension. For the pictures included in the mixed category, the semantic categories reported above the pictures were work tools (for sickle, scissors, hammer, brush, rake, palette, pincers, and drill), personal effects (for umbrella, pipe, and razor), habitations (for teepee), sweets (for candy), excursion tools (for hammock, binoculars, compass, map, and backpack), house objects (for antenna, candle, globe, radio, faucet, and clock), measurement tools (for hourglass and scale), sport articles (for helmet), toys (for skittle), jewels (for earrings), natural objects (for leaf), space objects (for planet), and plants (for cactus, palm tree, and ivy).

\section{Rating Procedure}

Within-category typicality. Thirty subjects took part in the present rating task, 15 for each type of sublist. Each subject was instructed to judge, with no pressure as to speed, how typical each picture was within the corresponding category by marking a value on the scale $(1=$ not typical; 7 = highly typical $)$.

Familiarity. Thirty subjects took part in the present rating task, 15 for each type of sublist. None participated in the typicalityrating task. Each subject was instructed to judge, with no pressure as to speed, how familiar the object depicted in each picture was, based on his/her own personal experience $(1=$ not familiar $; 7=$ highly familiar).

Age of acquisition. For the present rating task, each picture in the booklets was replaced with the corresponding name. ${ }^{1}$ Thirty subjects took part in the present rating task, 15 for each type of sublist. None participated in the typicality-and familiarity-rating tasks. Each subject was instructed to indicate, with no pressure as to speed, how old he/she was when he/she first encountered or received information about each word, using the 9-point scale reported below the picture $(1=2$ years or younger, $2=3$ years, $3=4$ years, $4=$ 5 years, $5=6$ years, $6=7 / 8$ years, $7=9 / 10$ years, $8=11 / 12$ years, and $9=13$ years or older .

\section{Speeded Naming Procedure}

Two different experimental sessions were required for the naming data collection. A list of 220 objects was presented in the first session. A list of 168 objects was presented in the second session. ${ }^{2}$ In each session, 44 subjects took part in the naming task. The experiment was carried out in a soundproof room, with the constant presence of a research assistant for response-scoring purposes. The pictures were displayed on the monitor of the computer (resolution, $640 \times 480$; cathode ray tube), and the vocal responses were recorded through a cardiod microphone. The monitor and microphone settings were controlled by a $166-\mathrm{MHz} \mathrm{CPU}$ and $\mathrm{MEL}$ software.

Each session consisted of three phases, each preceded by the presentation of written instructions on the monitor of the computer. The first phase was devoted to adjustment of microphone settings. Each subject was instructed to read, as fast and accurately as possible, a list of 10 words referring to abstract concepts, presented 1 at a time at the center of the monitor. An interval of $3 \mathrm{sec}$ elapsed between the presentation of 2 successive words. This phase was repeated if a single failure in detecting the subject's vocal response occurred. At each repetition, the sensitivity threshold of the microphone was lowered. The second phase was devoted to practice for the actual naming experiment. On each of eight trials, a fixation point was presented in the center of the monitor, which disappeared when the research assistant pressed a start button (the space bar on the keyboard of the computer). After pressing the space bar, an interval of $400 \mathrm{msec}$ elapsed before the presentation of a warning signal (a $1000-\mathrm{Hz}$ pure tone) for $100 \mathrm{msec}$. At tone offset, an interval of 700 msec elapsed before the presentation of a picture in the center of the monitor. The subjects were instructed to name each picture as fast and accurately as possible, trying to avoid the production of undesired noise (cough, hesitations, etc.). Each picture remained in view until a vocal response was detected. An interval of $2 \mathrm{sec}$ elapsed between response detection and the beginning of the next trial. The third phase was dedicated to data collection. Before the beginning of the third phase, the instructions stressed the importance of speed and accuracy during the whole experiment. Some rest during the experiment was allowed upon request of the subject. The order of picture presentation was fully randomized across subjects.

During the experiment, each response was scored by the research assistant, using the following scoring rule. A response could be correct (i.e., the name produced by the subject corresponded to the name assigned a priori to each picture), alternative (i.e., the name produced by the subject did not correspond to the assigned name), or invalid, reflecting microphone triggering by vocalizations that were not name productions.

\section{RESULTS}

\section{Trimming of the Naming Time Distribution}

The data from 2 subjects in each naming session were discarded because of software malfunctioning or because 
the rate of invalid responses exceeded the rate of both correct and alternative responses. Valid naming data were thus collected from 84 subjects. The analyses of the naming times (RTs) concentrated on correct responses. RTs were first screened for outliers, using a modification of the procedure proposed by Van Selst and Jolicœur (1994). The RTs for each picture were sorted, and the most extreme observation was temporarily excluded from consideration. The mean and standard deviation of the remaining values were then computed. Cutoff values were established, using the following equations:

$$
V_{\text {low }}=X-C_{n} * S D
$$

and

$$
V_{\text {high }}=X+C_{n} * S D .
$$

The smallest and largest observations were then checked against the cutoff values, $V_{\text {low }}$ and $V_{\text {high }}$. If one or both fell outside the bounds, these observations were excluded from further consideration and were defined as outliers. This algorithm was then applied anew to the remaining data. The value of $C$ depended on the sample size, $n$, so that the estimated final mean was not influenced by sample size. For samples of 100 or larger, $C$ is 3.5 , and the value of $C$ is increased nonlinearly as sample size decreases, to a maximum of 8.0 for a sample size of 4 . Note that, with this algorithm, outliers were calculated on the basis of the RT distribution for a given picture, not that for a given subject. This had the important implication of avoiding the elimination of RTs to difficult-to-name pictures, which obviously tended to fall into the slowest portion of the subject's RT distribution (see Snodgrass \& Yuditsky, 1996, for a discussion of this problem). The application of the outlier elimination procedure resulted in a total loss of $3.8 \%$ of the available RT data.

\section{Normative Data Description}

An Excel-formatted version of the normative data is available on line (http://olpss.psy.unipol.it/psychdata. $\mathrm{htm}$ ). The complete list of the normative data is reported in Appendix A. The first 2 columns of the list in Appendix A present the pictures' names (correct and alternative), in both Italian and English. Each alternative name (in lowercase, preceded by a right-pointing arrow) is associated with the percentage of subjects (in parentheses) who produced the alternative response. Each picture is associated with the following indexes. In the 3 rd column (labeled CAT), a three-letter abbreviation of the semantic category of each picture is reported (i.e., BIR, birds; FRU, fruits; VEH, vehicles; VEG, vegetables; MIX, mixed; WEA, weapons; BUI, building; FOR, furniture; INS, musical instruments; MAM, mammals; FLO, flowers; CLO, clothes; REC, receptacles; HOU, housewares). Number of letters and number of syllables of the pictures' names are reported in the 4th and 5th columns (labeled LET and SYL), respectively. Frequency values (log-transform of $1+$ number of occurrences over one million) of the printed pictures' names are reported in the 6th column (labeled FRQ). The source of the frequency values was Stella and Job's (in press) database. In the 7th column (labeled S), the number of the session in which the picture RTs have been collected is reported ( 1 , first session; 2 , second session). Mean familiarity values are reported in the 8th column (labeled FAM), together with the relative standard deviations in the 9 th column (labeled $S D$ ). Mean typicality values are reported in the 10 th column (labeled TYP), together with the relative standard deviations in the 11 th column $(S D)$. Mean age of acquisition values are reported in the 12th column (labeled AoA), together with the relative standard deviations in the 13 th column $(S D)$. Mean naming times are reported in the 14th column (labeled RT). Name agreement and concept agreement values are reported in the 15 th (labeled NA) and 16 th (labeled CA) columns, respectively. NA and $C A$ values are reported in the form of the percentages of subjects who produced the correct name (for NA) or the correct name plus synonyms (CA). Synonyms of the correct name (i.e., those whose NA value contributed to the computation of the CA value) are marked with an asterisk. When an NA value associated with a correct name is not the modal value (i.e., the correct name is not the most frequently produced name), all of the more frequent alternative names are marked with the symbol @. $H$ values (computed by using the equation described by Snodgrass \& Yuditsky, 1996) are reported in the 17th column (labeled $H$ ). A strict criterion (Snodgrass \& Vanderwart, 1980) was adopted to compute the $H$ statistic for each item, so that all names that were not identical to the correct name were considered in the computation.

\section{Stepwise Multiple Regression}

The matrix of partial correlation among the measures for the Italian sample is reported in Table $1 \mathrm{~A}$, and the results of the multiple regression analysis are reported in Table 1B. The overall equation for the multiple regression was significant $[R=.71 ; F(10,255)=25.82, p<$ $.0001]$. As can be seen from the results of the multiple regression analysis, the measures of CA and TYP and the $H$ statistic resulted in reliable predictors of the RT distribution. AoA figured as a significant predictor of the picture RTs in a separate regression in which CA values were temporarily excluded from consideration. This separate analysis was motivated by the possible masking effect on the potential reliability of AOA in accounting for the RT distribution, owing to the strong negative correlation between AoA and CA values, as is evidenced in the partial correlation matrix (see Edwards, 1979).

\section{Comparisons With Previous Studies}

Indirect comparisons with previous naming time studies. Although several studies in this field have reported standardized norms for different languages (see the forthcoming section), picture RTs have been collected in only two normative studies in which large samples of pictures $(N>200)$ were employed. In this section, we focus on an indirect comparison between the multiple 
Table 1A

Matrix of Partial Correlations Among the Italian Measures

\begin{tabular}{lrcrrrrrrr}
\hline Measures & \multicolumn{1}{c}{ RT } & \multicolumn{1}{c}{ LET } & \multicolumn{1}{c}{ SYL } & FRQ & FAM & TYP & AoA & NA & CA \\
\hline LET & n.s. & & & & & & & & \\
SYL & .164 & .852 & & & & & & & \\
FRQ & -.406 & -.345 & -.313 & & & & & & \\
FAM & -.249 & n.s. & n.s. & .236 & & & & & \\
TYP & -.231 & -.121 & n.s. & .343 & .457 & & & & \\
AoA & .472 & n.s. & .181 & -.519 & -.502 & -.321 & & & \\
NA & -.634 & -.165 & -.236 & .422 & .220 & .134 & -.492 & & \\
CA & -.671 & n.s. & -.182 & .426 & .238 & n.s. & -.540 & .933 & \\
H & .538 & n.s. & .172 & -.279 & -.148 & n.s. & .323 & -.798 & -.714 \\
\hline
\end{tabular}

Note-RT, naming time; LET, number of letters; SYL, number of syllables; FRQ, frequency; FAM, familiarity; TYP, typicality; AoA, age of acquisition; NA, name agreement; CA, concept agreement; n.s., nonsignificant.

regression results obtained in the present study and the results reported by Snodgrass and Yuditsky (1996, Experiment 1) and Barry et al. (1997). It is perhaps worth noting that RTs in these different studies have been trimmed according to different criteria for the elimination of outliers. Whereas Snodgrass and Yuditsky applied a criterion that is formally similar to the criterion adopted in the present study, Barry et al. used a reciprocal transformation of each picture's mean RT, following the elimination of RTs that were either shorter than $200 \mathrm{msec}$ or longer than $3,000 \mathrm{msec}$. Although it is generally accepted that $3,000 \mathrm{msec}$ is a reasonable constraint to adopt for the exclusion of what the authors treated as "major instances of word-finding difficulties," as was concluded by Snodgrass and Yuditsky, this may not be a viable method by which to prevent the possibility of systematically eliminating (informative) RTs to difficult-to-name pictures.

A summary of the multiple regression results from the present study and the two other studies mentioned is reported in Table 2A. The letter $\mathrm{x}$ is reported for those measures that resulted in reliable predictors of the RT distribution in each of the studies. When a measure did not enter into the regression equation in a given study, the measure is reported as nonsignificant (n.s.). When a partic-

Table $1 B$

Results of the Multiple Regression Analysis

\begin{tabular}{lcccc}
\hline Measure & $\beta$ & $S E$ & $t$ & $p$ \\
\hline LET & -.127 & .088 & 1.451 & .148 \\
SYL & .116 & .087 & 1.329 & .185 \\
FRQ & -.095 & .058 & 1.650 & .100 \\
FAM & -.002 & .056 & 0.030 & .976 \\
TYP & -.124 & .053 & 2.356 & .019 \\
AoA & .077 & .064 & 1.192 & .234 \\
& $(.138)$ & $(.065)$ & $(2.118)$ & $(.035)^{*}$ \\
NA & .156 & .147 & 1.060 & .290 \\
CA & -.598 & .132 & 4.529 & .000 \\
$H$ & .163 & .075 & 2.183 & .030 \\
\hline
\end{tabular}

Note-For each measure, beta weight $(\beta)$, standard error $(S E), t$ statistic value $(t)$, and level of probability $(p)$ are reported. LET, number of letters; SYL, number of syllables; FRQ, frequency; FAM, familiarity; TYP, typicality; AoA, age of acquisition; NA, name agreement; CA, concept agreement. *AoA results after the temporary exclusion of $C A$ values from the stepwise regression. ular measure was not considered in a study, the measure is reported as nonavailable (n.a.).

Table 2A highlights both the similarities and the differences among the studies. The first important difference is represented by the fact that the TYP measures were collected and treated as an independent factor only in our normative study. This difference is all the more striking in light of the evidence that TYP is a relevant cognitive dimension when concepts must be categorized (Rosch, 1975) and that TYP plays a significant role in modulating picture RTs (see, e.g., Jolicœur, Gluck, \& Kosslyn, 1984), as well as other behavioral dependent measures (e.g., Malt \& Smith, 1984). Convergent with this earlier empirical evidence, the results of the stepwise multiple regression that we performed on our data set support the notion that TYP must be considered in studies in which RTs are used as a dependent variable or, more generally, in studies in which pictures are used as experimental stimuli.

Table 2A also shows that measures of NA consistently resulted in reliable predictors of the RT distribution. It is somewhat surprising that, contrary to all other studies, $\mathrm{NA}$, in the form of the percentage of subjects who produced a given name in response to a particular picture, was not an element of the regression equation in the present study. In our view, this finding may reflect the fact that, in quite a large proportion of the cases in the present study, alternative names that were produced were "good" lexical substitutes (i.e., synonyms) of the correct names. This had the likely consequence that variations in the percentage of NA (which decreases as the number of alternatives increases) could not be directly reflected in the RT distribution. Additional information about the role of stimulus codability, however, is provided by the significant weight associated with both the $H$ statistic (considered in all the studies) and measures of CA (considered only by Snodgrass \& Yuditsky, 1996) in accounting for the RTs collected in the present study. As has been convincingly argued by many investigators (e.g., Alario \& Ferrand, 1999; Lachman, 1973; Lachman, Shaffer, \& Hennrikus, 1974; Snodgrass \& Vanderwart, 1980; Snodgrass \& Yuditsky, 1996), both $H$ and CA measures can 
Table 2A

\begin{tabular}{|c|c|c|c|c|c|c|c|c|c|}
\hline Study & LET & SYL & FRQ & FAM & TYP & AoA & NA & $\mathrm{CA}$ & $H$ \\
\hline Present & n.s. & n.s. & n.s. & n.s. & $x$ & $x$ & n.s. & $x$ & $x$ \\
\hline S\&Y & n.s. & n.s. & $x^{*}$ & $x^{*}$ & n.a. & $x$ & $x$ & $x$ & $x$ \\
\hline $3 M \& E$ & n.s. ${ }^{*}$ & n.a. & $x$ & n.s. & n.a. & $x$ & $x$ & n.a. & \\
\hline
\end{tabular}

Note-LET, number of letters; SYL, number of syllables; FRQ, frequency; FAM, familiarity; TYP, typicality; AoA, age of acquisition; NA, name agreement; CA, concept agreement; n.s., nonsignificant; n.a., nonavailable; $x$, significant beta weight; $x^{*}$, negligible beta weight. *Picture name length measures as number of phonemes.

be taken as better indexes of stimulus codability with respect to the raw percentage of correct denominations. The $H$ statistic is computed by taking into account the number of alternatives produced following the presentation of a particular picture. $H$ differs for pictures having the same percentage of NA but different numbers of alternative names produced by subjects. Furthermore, CA estimates reflect the degree of semantic appropriateness of alternative denominations--that is, CA varies as a function of whether alternative names are synonyms of the correct names or names referring to semantically distinguishable concepts. Given two pictures with the same percentage of NA and the same number of alternative names, $\mathrm{CA}$ is higher if one picture elicits more synonyms than does the other.

Table 2A indicates that a significant role for AoA measures was found in all of the three studies. Furthermore, AoA turns out to be a better predictor of RTs than are both FAM (nonsignificant or negligible in all the studies) and FRQ (significant in Barry et al.'s, 1997, work only). It should be noted that, while it might be theoretically relevant to ponder the higher reliability of AoA in predicting picture RTs as compared with FAM (see Morrison, Ellis, \& Quinlan, 1992, for details on this issue), our impression is that the discussion about the rather variable weight of FRQ in the three regressions examined in the present context may be limited to the choice of the different FRQ count databases. Specifically, as Snodgrass and Yuditsky (1996; see also Snodgrass \& Vanderwart, 1980) did in their study, we used an FRQ count database of written words (Stella \& Job, in press). Barry et al. reported results that were referred to a FRQ count database of spoken words. The latter was, reasonably, a choice more compatible with the vocal responses subjects had to produce in all the studies (i.e., naming) and may account for the fact that FRQ had a significant weight only in Barry et al.'s study.

Table 2A shows also that word length measures (number of letters, phonemes, or syllables) did not play a significant role in determining the RT distribution in any of the three studies.

Direct comparisons with previous normative studies. One potential confound in the comparison described in the foregoing section resides in the fact that the number of independent variables entering into the different regression equations was necessarily limited. For this reason, it is important to note that the list of these variables (e.g., FAM, AoA, etc.) constitutes only a subset of all the variables that might potentially affect object naming. In each normative study listed in Table $2 \mathrm{~A}$, the choice of the independent variables hypothesized to account for the RT distribution was substantially determined by three factors - namely, by previous evidence that demonstrated the effective role of a particular independent variable in influencing object naming, by theoretically grounded predictions about the possible role that an independent variable might play in object processing, or by the need to select a set of independent variables common to the majority of studies, with the aim of estimating their relative weight in affecting performance on objects across cultures.

Concerning the latter point, with the view of providing a direct comparison between the present norms and norms standardized for different populations, a potential confound may be represented by the difference in the drawings used for data collection. For the sake of clarity, suppose that we have two different pictures of the same concept-say, a pitcher-and suppose that each picture has been associated with a different NA value following a rating procedure carried out by presenting one picture to Italian subjects and the other picture to American subjects. As a matter of fact, it is impossible to assess whether this difference is due to a pure cultural difference in the subjects' population or to a structural difference in the pictures submitted to the subjects' judgment (or to an interaction between these two factors). It might be that, for example, the picture presented to the Italian subjects was less detailed than the American picture, and this, in turn, might have been reflected in a higher degree of uncertainty about its identity (Is it a pitcher or a mug?). Similar examples can be offered for the other independent variables considered in our normative study, with all the examples pointing to the same problem - that is, the impossibility of distinguishing between cultural and structural factors in determining the values assigned to the rated dimensions.

Fortunately in our case, this problem can be solved by taking advantage of the presence, in the literature, of Italian norms from a study in which Snodgrass and Vanderwart's (1980) stimuli were used (Nisi et al., 2000) and for which data were collected for a subset of measures 
that were also included in our study (i.e., for FAM, AoA, and NA). Furthermore, a fair number of concepts $(N=$ 105, reported in Appendix B) were common to our study and that of Snodgrass and Vanderwart. The method we propose to use to disentangle cultural and structural influences on the measures provided for our new stimuli hinges on the following logic. We assume that the correlation coefficient between our measures and the measures collected by Nisi et al. for the common set of concepts provides the benchmark of the influence of structural factors on the distribution of the rating values across the stimuli. That is, given that our subjects and Nisi et al.'s subjects can be thought of as having been taken from the same population (Italian university students), our hypothesis is that any deviation from the perfect correlation between our measures and those of Nisi et al. can be reasonably accounted for by a difference in the stimuli used in the respective normative studies. Our next step is to compare each of these correlation coefficients with the correlation coefficients between our measures and the measures collected for American, French, and Spanish and to interpret any significant difference among these correlation coefficients as indicators of the effective influence of cultural differences on the distribution of the rating values across the stimuli. ${ }^{3}$

A list of the correlation coefficients for the measures from the different studies is reported in Table 2B. Several comments are in order. The first comment is related to the influence of structural factors on the distribution of the values for the measures collected on the two Italian samples. Evidence concerning this point can be derived from the observation of the correlation coefficients between the measures collected in our study and those collected in Nisi et al.'s (2000) study. These correlation coefficients are reported in bold in Table 2B. As is clear, although FAM and AoA measures are highly correlated in the two studies, the degree of correlation between NA

Table 2B

Correlation Coefficients Between a Subset of the Present Measures and the Measures From a Different Italian Sample Collected Using Snodgrass and Vanderwart's Pictures (Nisi, Longoni, \& Snodgrass, 2000), From an American Sample (Snodgrass \& Vanderwart, 1980, for Familiarity, Frequency, and $H$ measures, and Snodgrass \& Yuditsky, 1996, for Age of Acquisition Measures), From a French Sample (Alario \& Ferrand, 1999), and From a Spanish Sample (Sanfeliu \& Fernandez, 1996)

\begin{tabular}{ccccc}
\hline $\begin{array}{c}\text { Measures From } \\
\text { Present Study }\end{array}$ & Italian & American & French & Spanish \\
\hline FAM &. $\mathbf{7 2}$ & .68 & .71 & $.46^{*}$ \\
AoA & $\mathbf{. 9 1}$ & $.80^{*}$ & .87 & n.a. \\
$H$ & $\mathbf{. 5 1}$ & $.28^{*}$ & .36 & $.23^{*}$ \\
FRQ & $\mathbf{1 . 0 0}$ & $.67^{*}$ & $.74^{*}$ & $.74^{*}$ \\
\hline
\end{tabular}

Note-FAM, familiarity; AoA, age of acquisition; $H, H$ statistic: FRQ, name frequency; n.a., nonavailable. ${ }^{*} p<.05$. The table provides indications on the results of $z$ tests performed by comparing the correlation coefficients between the present measures and the Italian NL\&S's measures (in bold) to the correlation coefficients between the present measures and, in turn, the American, French, and Spanish measures. measures, although substantial, is somewhat lower than that for the other measures. Although a systematic investigation of this issue is beyond the scope of the present work, we think we have already provided hints for an explanation for this relatively low correlation between NA measures. The framework we have adopted in the present section leads us to suspect that the interpretation resides in a difference in the material used for data collection, with NA values being a function of the number and/ or the quality of the details reported for the pictures used in the different studies. It is perhaps worth noting that our sample, in general, showed less variability in the number of alternative names produced in response to the presentation of the pictures than Nisi et al.'s sample did $[t(104)=$ $6.91, p<.001]$. Furthermore, this result also suggests that, whereas NA is influenced by structural information, as was suggested by Sanfeliu and Fernandez (1996), FA and AoA values are produced directly by the concept represented by a given picture.

Cultural differences emerge by comparing the magnitudes of the correlations between the two Italian samples with those between our measures and those of the foreign samples. At first blush, the pattern of correlations among the values provided by our sample and the "foreign" values seem to reflect the pattern of correlations between the values from the two Italian samples. As is evident for each sample, correlations are higher for FAM and AoA values and lower for NA values. This pattern of results was expected, on the assumption that NA values depend on language more than do the other measures. Similar results have been reported basically by all the studies in which formally equivalent comparisons have been performed (e.g., Alario \& Ferrand, 1999; Sanfeliu \& Fernandez, 1996). Significant differences between these correlation coefficients are marked with asterisks in Table 2B. Focusing first on the results of the $z$ tests performed on the correlation coefficients among NA measures, the results in Table 2B suggest that cultural differences play a significant role only in the comparison between the Italian values $(r=.51)$ and both the American English and the Spanish values ( $r=.28$ and .23, respectively). The correlation between the Italian and the French values do not reflect any cultural difference on the distribution of NA values, with the correlation coefficient between our values and the French values $(r=.36)$ being statistically comparable with the correlation coefficient between the two Italian samples. A cultural difference is also evident in the results for the FAM measure. Whereas the correlation between our Italian values and both the American and the French values $(r=.68$ and .71 , respectively) is high and comparable with the correlation for the Italian-Italian values $(r=.72)$, the significant difference of the Italian-Spanish correlation coefficient $(r=.46)$ suggests that that two populations differ in the degree of FAM with the same concepts. As to the AoA measures (collected only in the American and French studies), the results reported in Table $2 \mathrm{~B}$ in- 
dicate that, contrary to the correlation between the Italian and the French values $(r=.87)$, the correlation between the Italian and the American values $(r=.80)$ is significantly different from the Italian-Italian correlation coefficient and suggest that the distribution of AoA values across the same set of stimuli is effectively influenced by cultural factors. Finally, name FRQ measures were assumed to be perfectly correlated between the two Italian studies. This likely caused the $z$ test among all the other correlation coefficients to be highly sensitive to any deviations from $r=1$. Table 2B shows that all the comparisons between the Italian-Italian correlation coefficient for frequency and the Italian-foreign correlation coefficients, although quite high $(r>.67)$ in all cases, consistently resulted in a significant difference.

\section{CONCLUSIONS}

The main goal of the present work was to present Italian normative measures for a new set of 266 pictures that have been standardized for NA, FRQ, TYP, and RT. These pictures can thus be directly used in research with Italianspeaking subjects. It is our opinion that these pictures will be useful for researchers involved in different fields of experimental psychology, such as attention, memory, perception, and language. The regression analyses presented in this work have documented the significant role that a subset of the rated object dimensions has in determining subjects' naming performance on these objects. Concerning this point, the present results indicated that a particular dimension, TYP, which has never been taken into consideration in previous normative studies, plays a determinant role in object naming, with pictures of more typical elements being named faster than pictures of less typical elements. An indirect comparison with previous naming studies has indicated both similarities and differences, across the Italian, American, and English samples, in the type and number of object dimensions that affect picture RT. For instance, whereas the $H$ statistic and CA seem to be robust predictors of the RT, a substantial fluctuation in weight has been evidenced for name FRQ and FAM across the studies considered in the present work.

Furthermore, with the view of (1) making apparent the discrepancies between the present normative measures and the measures provided for linguistically different samples (collected by using Snodgrass \& Vanderwart's, 1980 , pictures) and (2) encouraging the use of the present set of pictures in order to expand research potentialities, a set of comparisons has been carried out, in order to show the relative weight of structural and cultural factors in generating such differences. An estimate of the weight of structural factors on the values reported in the present work has been provided through the correlation between the present measures and a subset of Italian measures collected by using Snodgrass and Vanderwart's pictures. This gave us the opportunity, by performing a series of $z$ tests on the correlation coefficients between the present measures and the measures provided for nonItalian samples, to separate the influence of structural from cultural factors in the rated dimensions.

\section{REFERENCES}

Alario, F.-X., \& Ferrand, L. (1999). A set of 400 pictures standardized for French: Norms for name agreement, image agreement, familiarity, visual complexity, image variability, and age of acquisition. $B e$ havior Research Methods, Instruments, \& Computers, 31, 531-552.

Barry, C., Morrison, C. M., \& Ellis, A. W. (1997). Naming the Snodgrass and Vanderwart pictures: Effects of age of acquisition, frequency, and name agreement. Quarterly Journal of Experimental Psychology, 50A, 560-585.

Berman, S., Friedman, D., Hamberger, M., \& Snodgrass, J. G. (1989). Developmental picture norms: Relationships between name agreement, familiarity, and visual complexity for child and adult ratings of two sets of line drawings. Behavior Research Methods, Instruments, \& Computers, 21, 371-382.

Cycowicz, Y. M., Friedman, D., Rothstein, M., \& Snodgrass, J. G. (1997). Picture naming by young children: Norms for name agreement, familiarity, and visual complexity. Journal of Experimental Child Psychology, 65, 171-237.

EDWARDS, A. L. (1979). Multiple regression and the analysis of variance and covariance. New York: W. H. Freeman.

Ellis, A. W., \& Morrison, C. (1998). Real age-of-acquisition effects in lexical retrieval. Journal of Experimental Psychology: Learning, Memory, \& Cognition, 24, 515-523.

Feenan, K., \& Snodgrass, J. G. (1990). The effect of context on discrimination and bias in recognition memory for pictures and words. Memory \& Cognition, 18, 515-527.

Jolicaeur, P., Gluck, M. A., \& Kosslyn, S. M. (1984). Pictures and names: Making the connection. Cognitive Psychology, 16, 243-275.

LACHMAN, R. (1973). Uncertainty effects on time to access the internal lexicon. Journal of Experimental Psychology, 99, 199-208.

Lachman, R., Shaffer, J. P., \& HenNrikus, D. (1974). Language and cognition: Effects of stimulus codability, name-word frequency, and age of acquisition on lexical reaction time. Journal of Verbal Learning \& Verbal Behavior, 13, 613-625.

LotTo, L., Dell'ACQuA, R., \& JoB, R. (in press). Le figure PD/DPSS: Misure di accordo sul nome, tipicità, familiarità, età di acquisizione e tempi di reazione per 266 figure [The PD/DPSS pictures: Norms for name agreement, typicality, familiarity, age of acquisition, and naming times for 266 pictures]. Giornale Italiano di Psicologia.

LotTo, L., Rumiat, R., \& Job, R. (1996). The picture superiority effect in categorization: Visual or semantic? Journal of Experimental Psychology: Learning, Memory, \& Cognition, 18, 1019-1028.

MalT, B. C., \& SMITH, E. E. (1984). Correlated properties in natural categories. Journal of Verbal Learning \& Verbal Behavior, 23, 250-269.

MARTEIN, R. (1995). Norms for name and concept agreement, familiarity, visual complexity and image agreement on a set of 216 pictures. Psychologica Belgica, 35, 205-225.

Morrison, C. M., Ellis, A. W., \& Quinlan, P. T. (1992). Age of acquisition, not word frequency, affects objects naming, not object recognition. Memory \& Cognition, 20, 705-714

Nisi, M., Longoni, A. M., \& SNodgrass, J. G. (2000). Misure italiane per l'accordo sul nome, familiarità ed età di acquisizione, per le 260 figure di Snodgrass e Vanderwart (1980) [Italian norms for name agreement, familiarity, and age of acquisition for the S\&V (1980) set of pictures]. Giornale Italiano di Psicologia, 27, 205-218.

Rosch, E. (1975). Cognitive representation of semantic categories. Journal of Experimental Psychology: General, 104, 192-233.

Sanfeliu, M. C., \& Fernandez, A. (1996). A set of 254 SnodgrassVanderwart pictures standardized for Spanish: Norms for name agreement, image agreement, familiarity, and visual complexity. $B e$ havior Research Methods, Instruments, \& Computers, 28, 537-555. 
SNODGRaSS, J. G. (1984). Concepts and their surface representations. Journal of Verbal Learning \& Verbal Behavior, 23, 3-22.

SNODGRASs, J. G., \& CoRwIN, J. (1988). Perceptual identification thresholds for 150 fragmented pictures from the Snodgrass and Vanderwart picture set. Perceptual \& Motor Skills, 67, 3-36.

SnODgrass, J. G., \& FeEnan, K. (1992). Priming effects in picture fragment completion: Support for the perceptual closure hypothesis. Journal of Experimental Psychology: General, 119, 276-298.

SNOdGRass, J. G., \& McCullough, B. (1986). The role of visual similarity in picture categorization. Journal of Experimental Psychology: Learning, Memory, \& Cognition, 12, 147-154.

SnODGRASS, J. G., \& POSTER, M. (1992). Visual-word recognition thresholds for screen-fragmented names of the Snodgrass and Vanderwart pictures. Behavior Research Methods, Instruments, \& Computers, 24, 1-15.

Snodgrass, J. G., \& VANDERWART, M. (1980). A standardized set of 260 pictures: Norms for name agreement, image agreement, familiarity, and visual complexity. Journal of Experimental Psychology: Human Learning \& Memory, 6, 174-215.

Snodgrass, J. G., \& Yuditsky, T. (1996). Naming times for the Snodgrass and Vanderwart pictures. Behavior Research Methods, Instruments, \& Computers, 28, 516-536.

Stella, V., \& Joв, R. (in press). Frequenza sillabica e frequenza di lemmi della lingua italiana scritta [Syllabic and lemma frequency for written Italian]. Giornale Italiano di Psicologia.

VANDERWART, M. (1984). Priming by pictures in lexical decision. Journal of Verbal Learning \& Verbal Behavior, 23, 67-83.

VAN SELST, M. E., \& Jolicheur, P. (1994). A solution to the effect of sample size on outlier elimination. Quarterly Journal of Experimental Psychology, 47A, 631-650.

\section{NOTES}

1. As an alternative to the retrospective method used in the present context to obtain estimates of age of acquisition ( $A \circ A)$, several more direct (and arguably more objective) methods may be proposed. For instance, Ellis and Morrison (1998) recently reported AoA measures based on the actual naming performance of children of different ages, which is probably the best candidate among these new proposals. Our choice of the particular method described in this section, however, is to be thought of as constrained by the main focus of the paper, which is to devise a direct comparison with previously published work in the normative field. For this reason, we had to commit to the tradition of (1) using retrospective judgments of $A o A$, (2) submitting to subjects, in the AoA rating session, a verbal representation of the concepts considered (i.e., words), and (3) stressing, in the instructions, the importance of focusing on the concept each word referred to.

2. Part of the material presented in the first session was also presented in the second session. The second session served the purpose of presenting new objects that were made available by the time the first session had already began. In an attempt to counterbalance the number of items presented across sessions, new objects were intermixed with objects presented in the first session, whose NA percentage value was greater than $90 \%$.

3. In order to apply the method described in the present section, all the scores (reported in Appendix B) were transformed into standard $z$ scores. Each correlation coefficient was then transformed into Fisher's $z$, and a $z$ test was carried out to estimate the difference between two correlation coefficients. If the difference was greater than 1.96 , the difference was taken to be significant with .95 probability. 


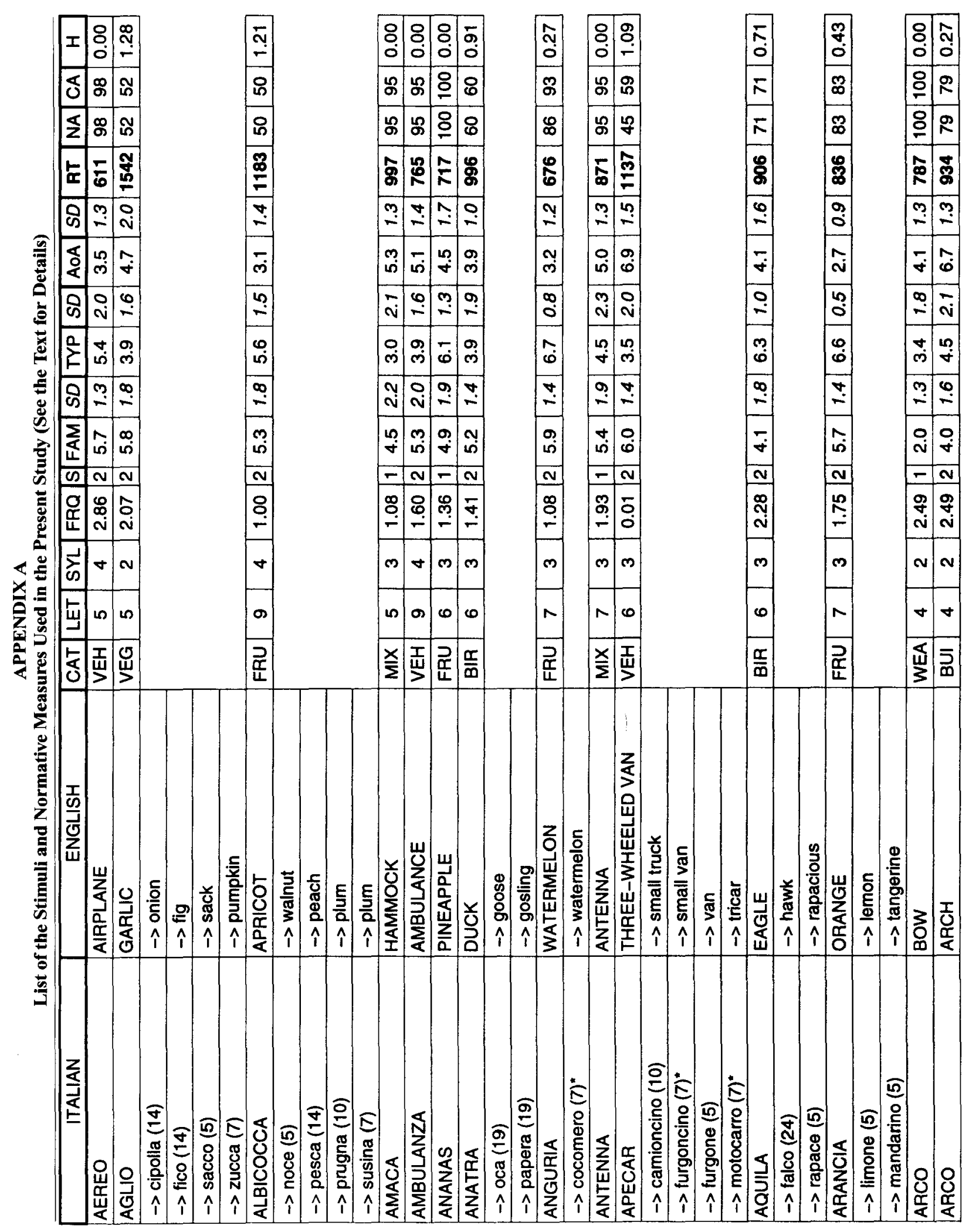




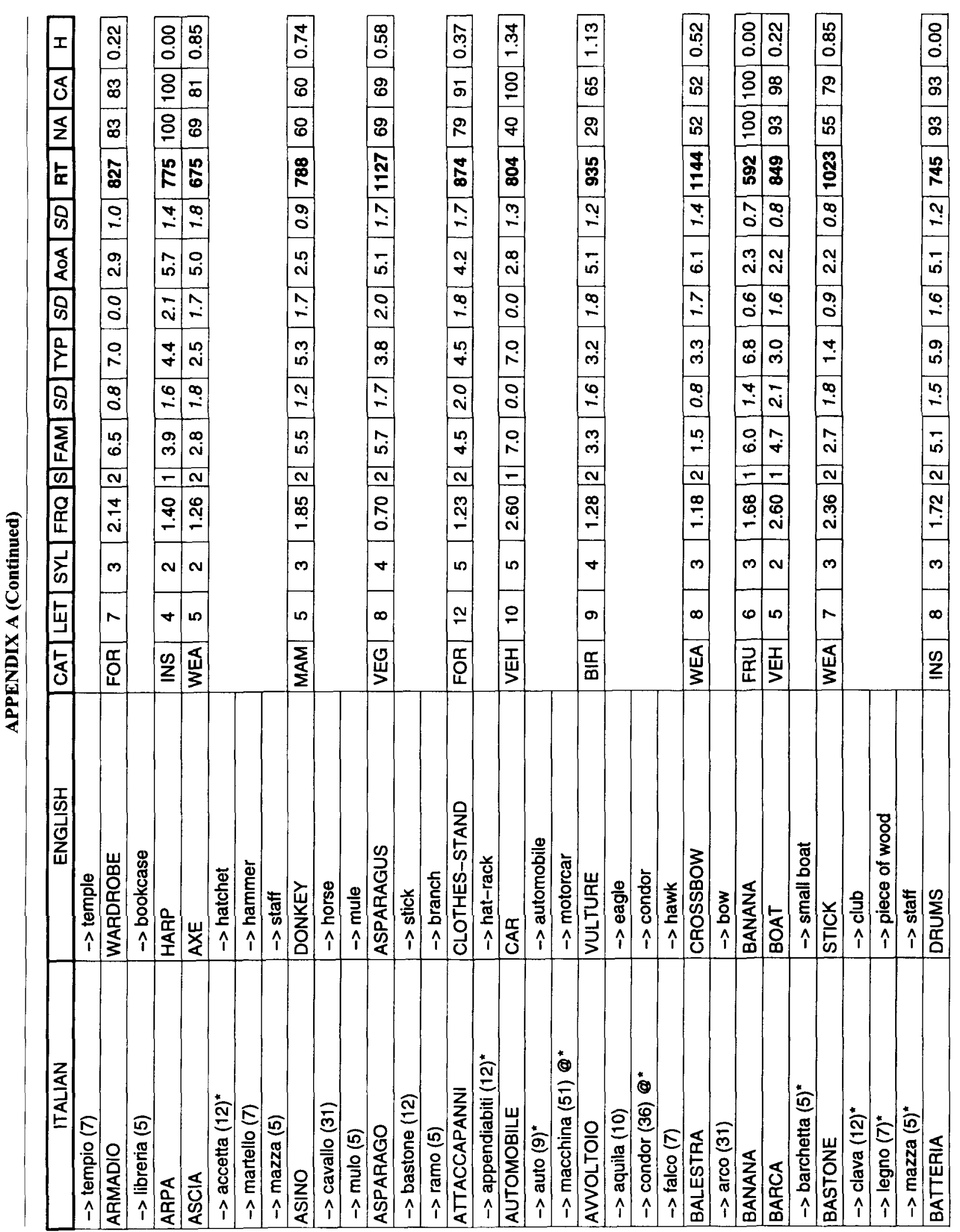




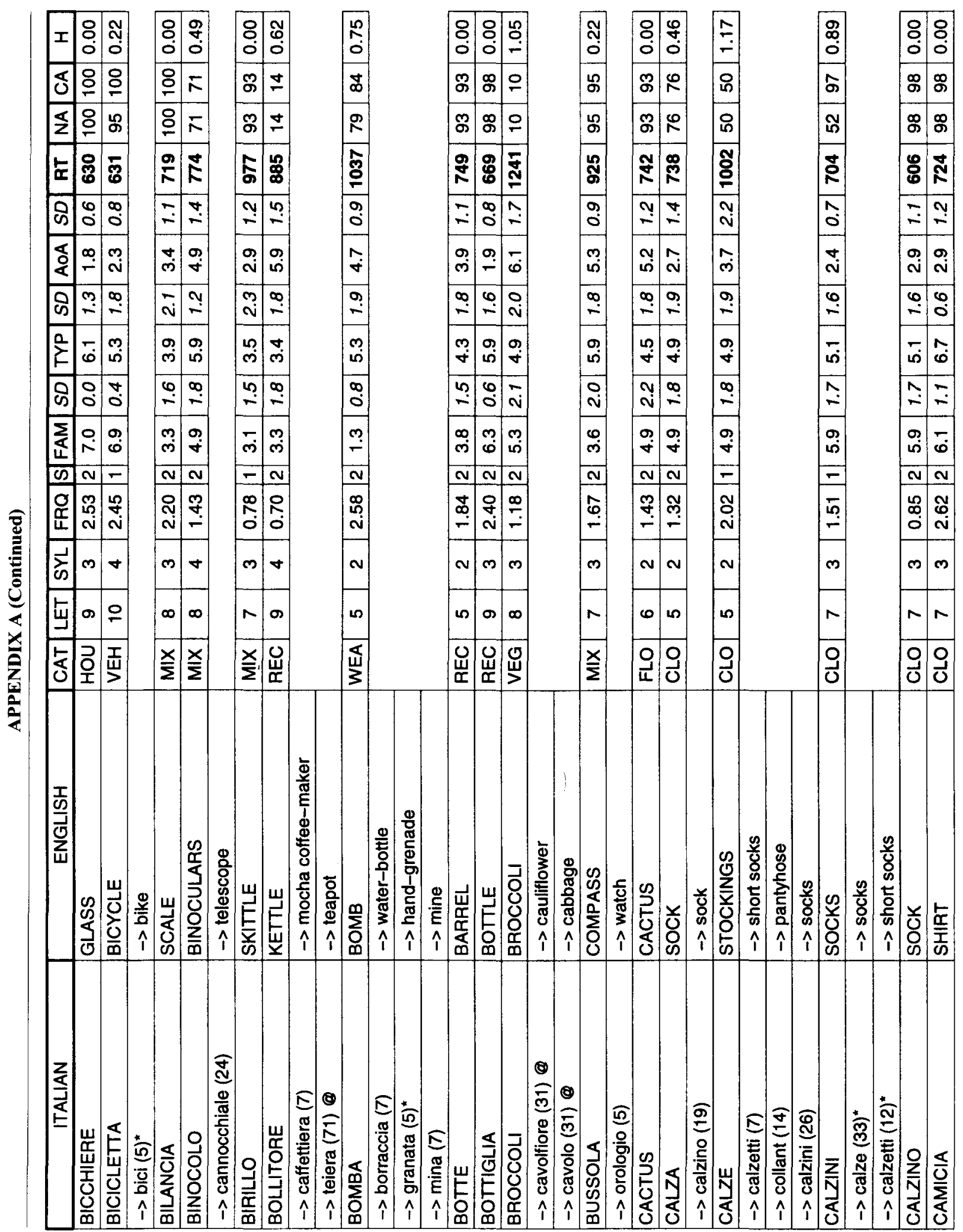




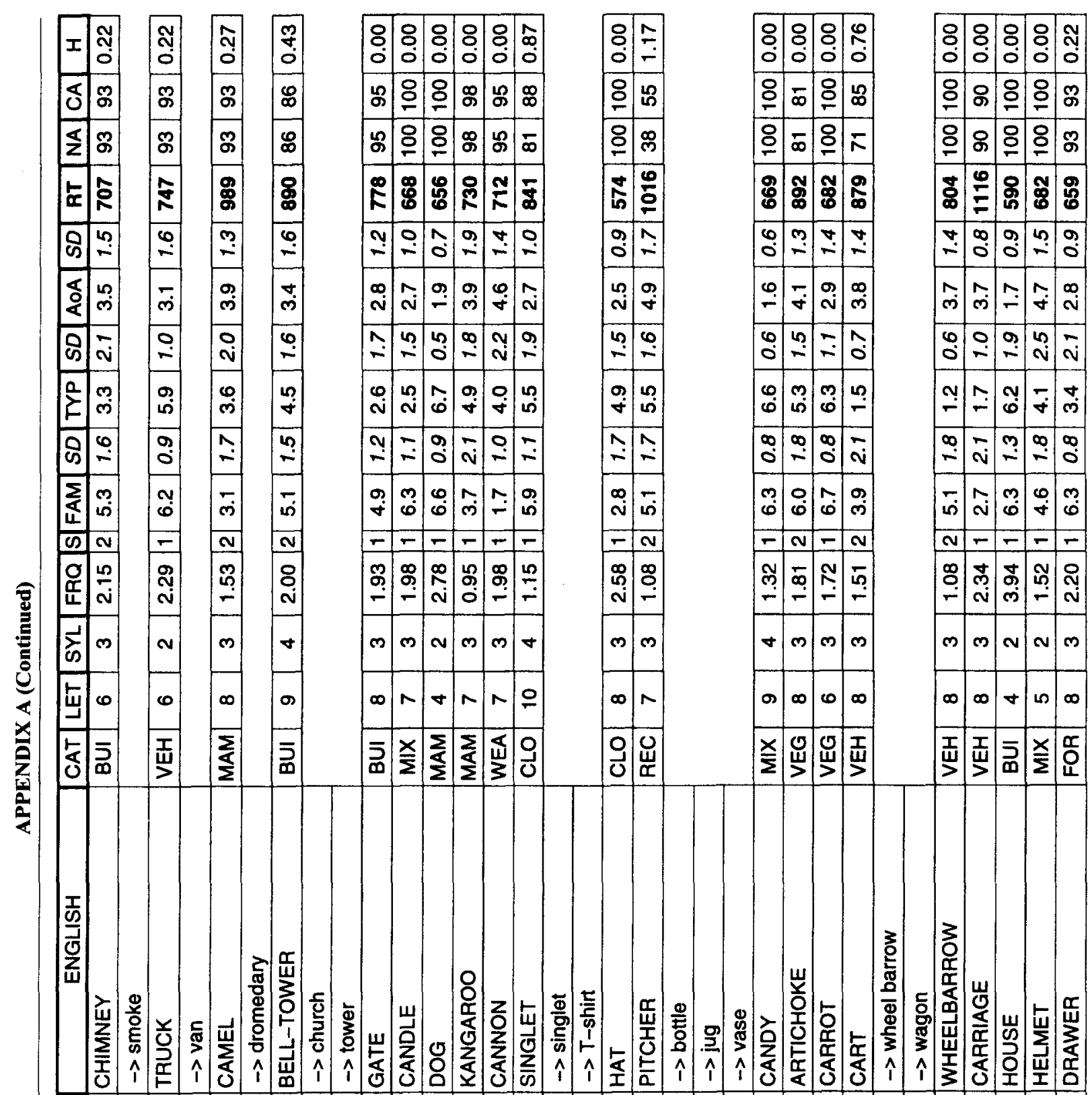

走

E

ลิ

또을

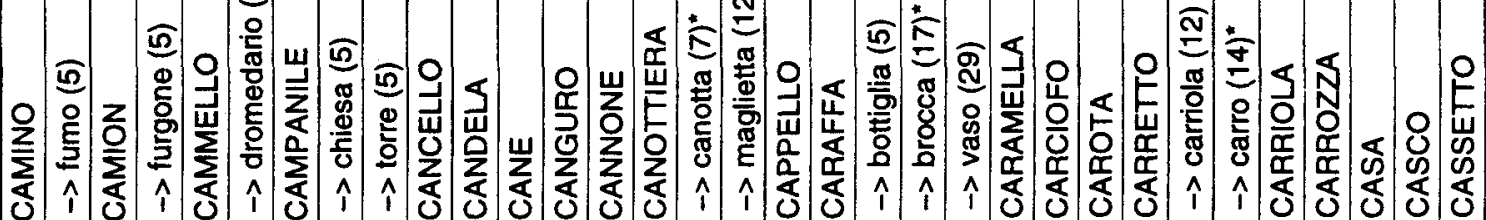




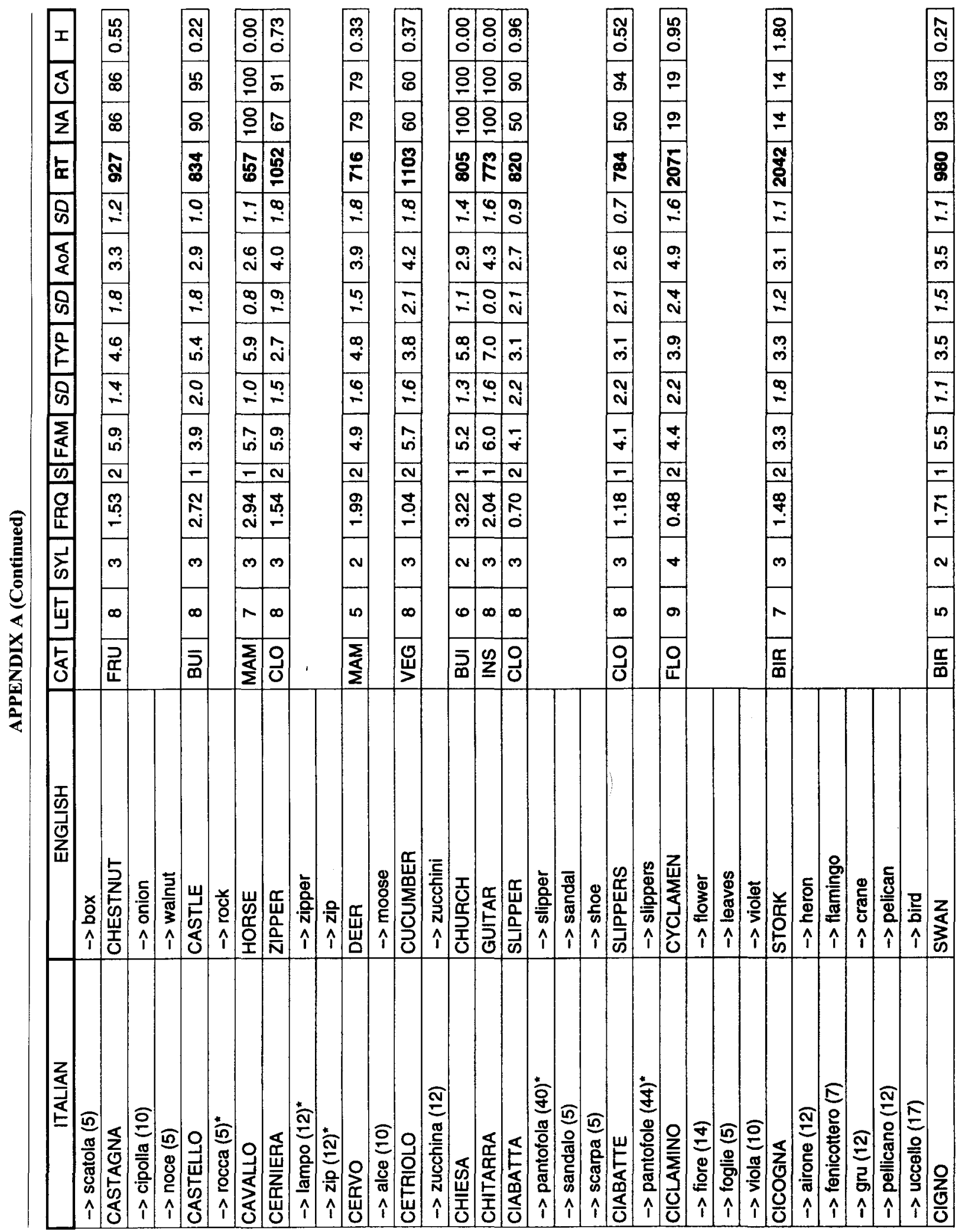




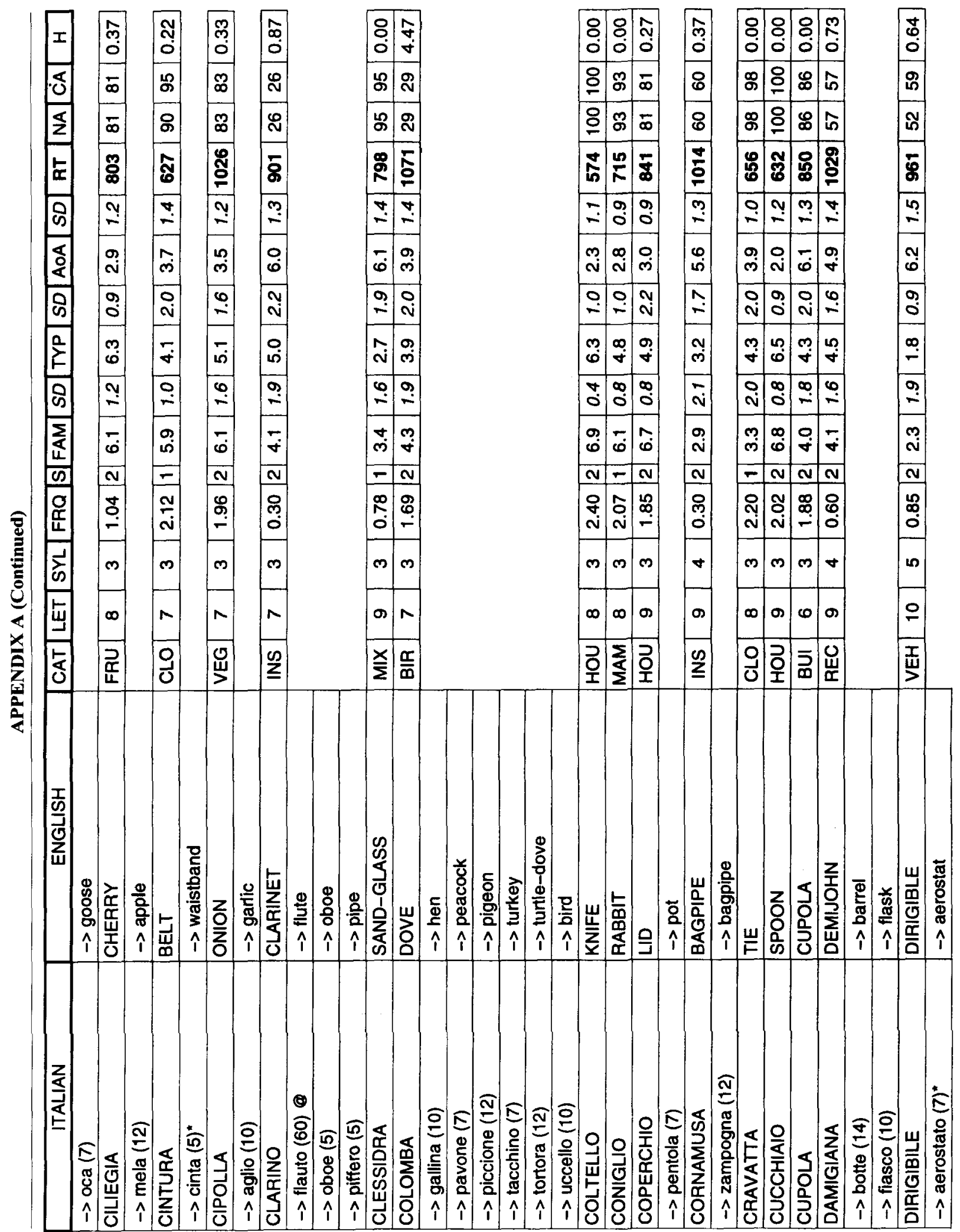




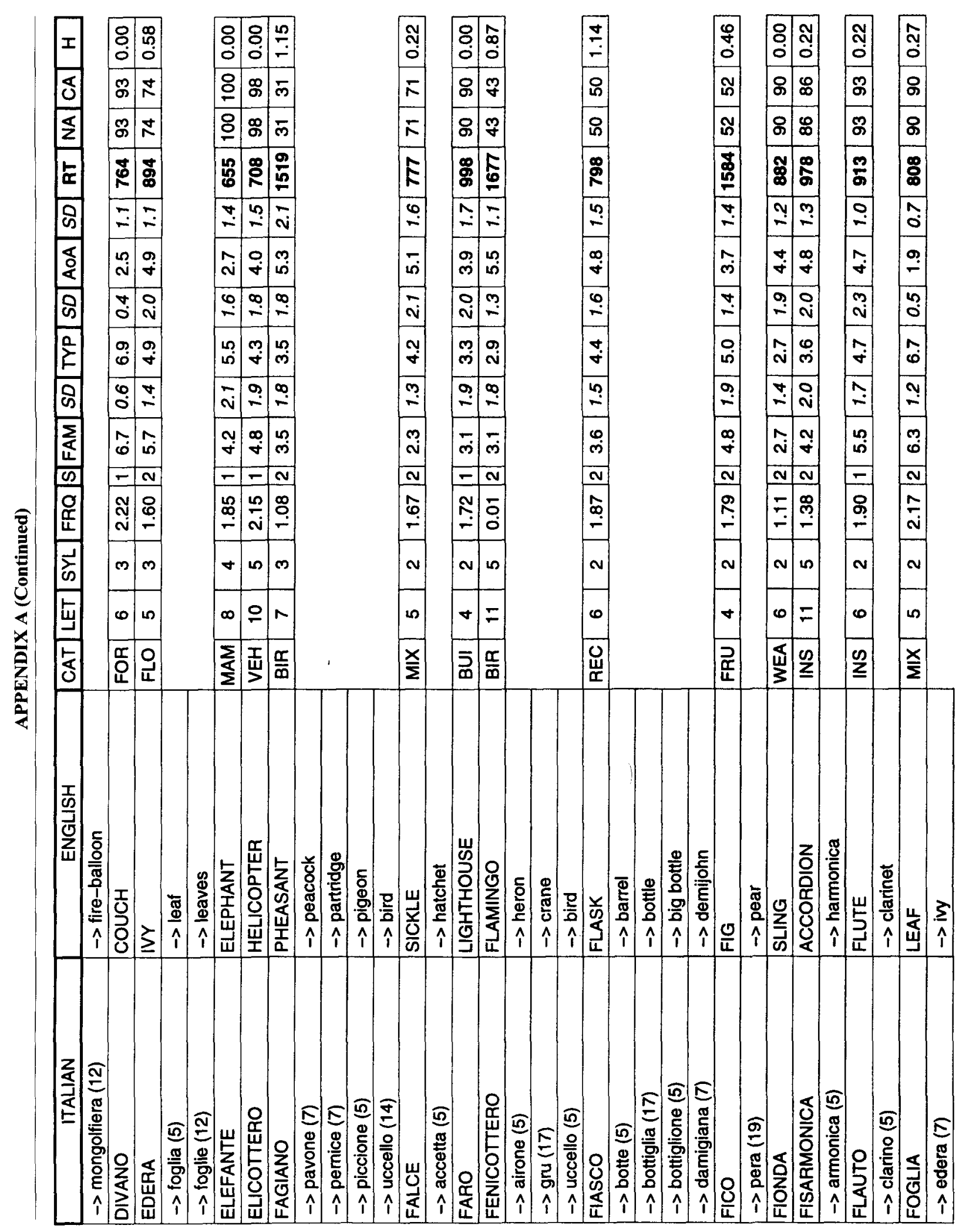




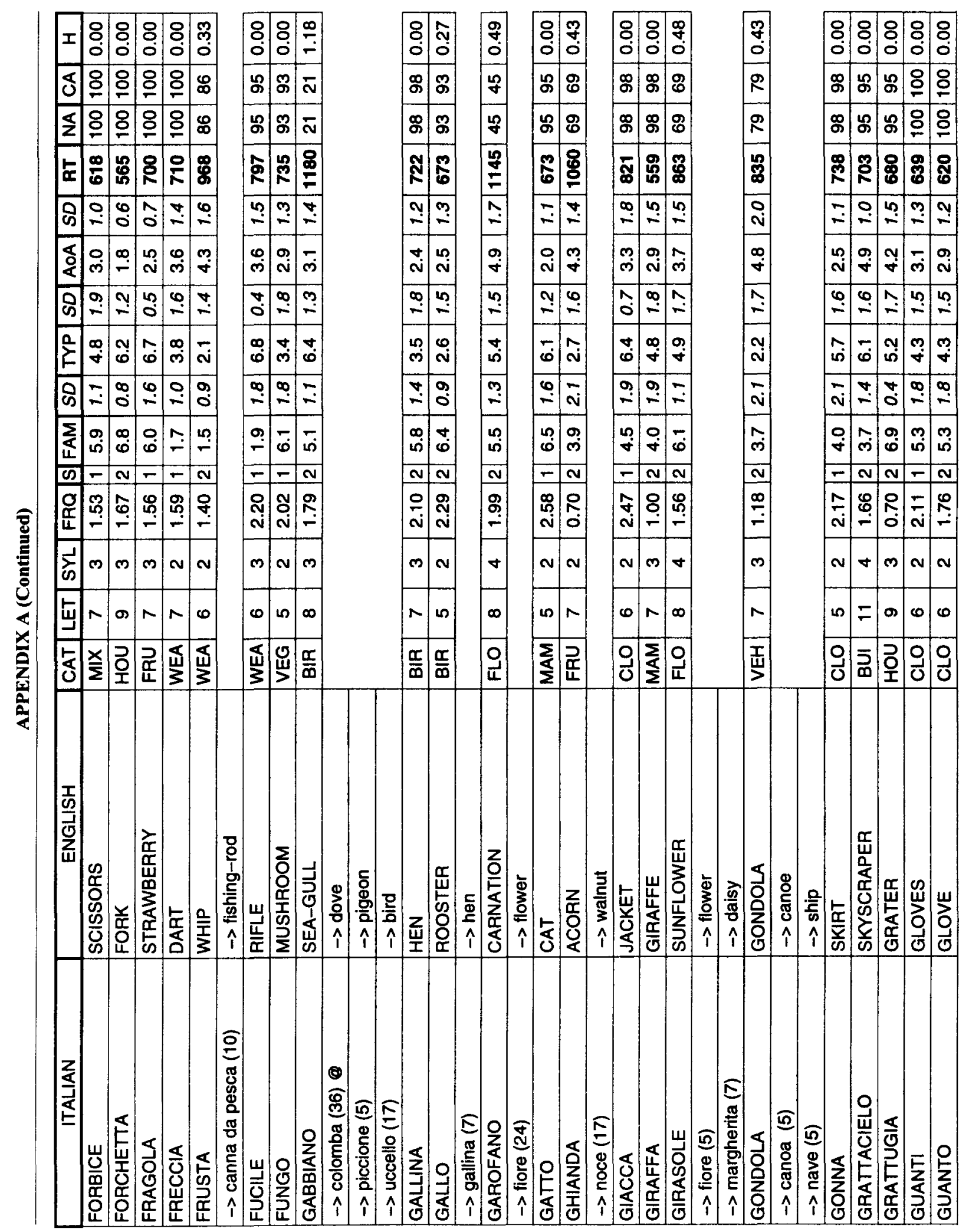




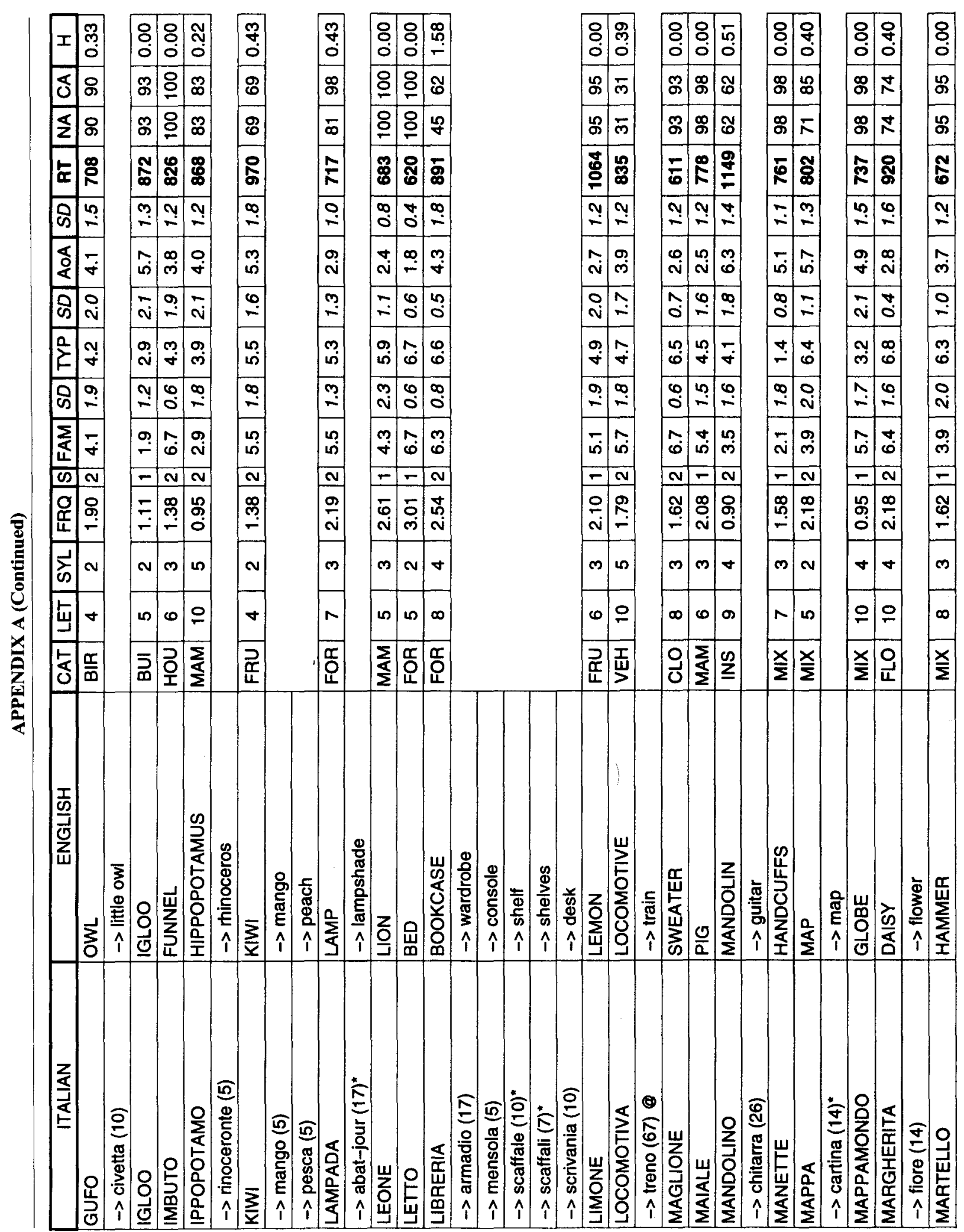




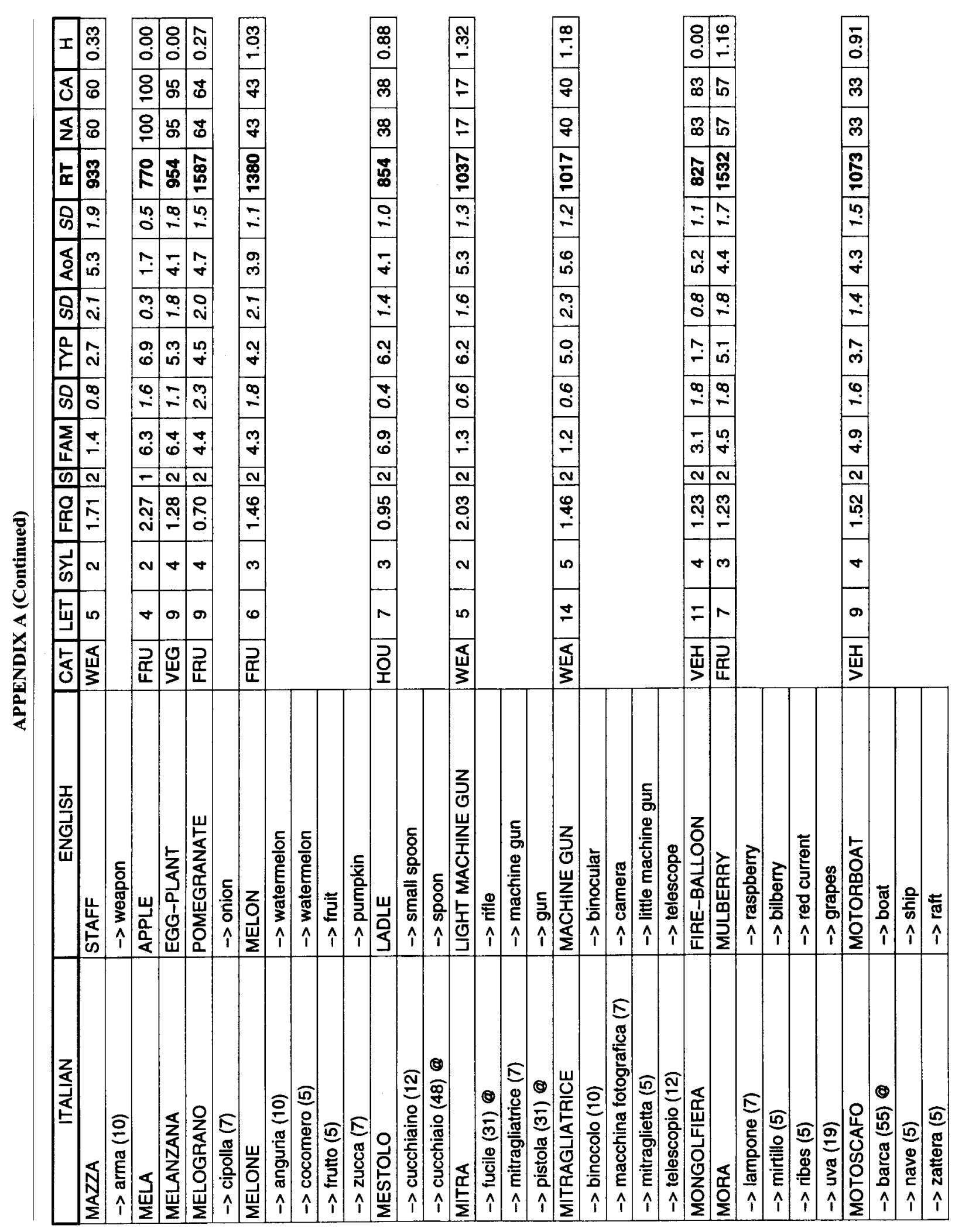




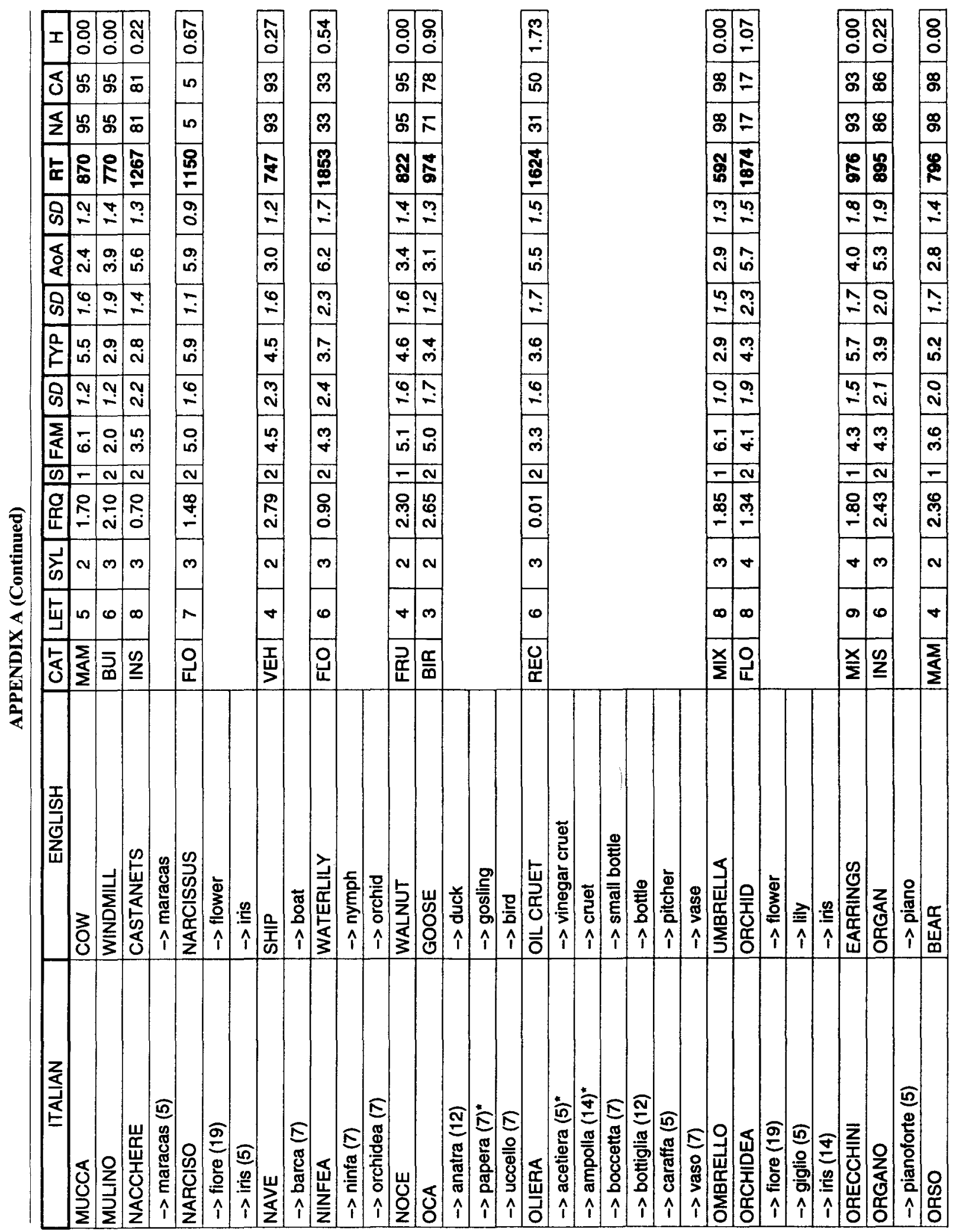




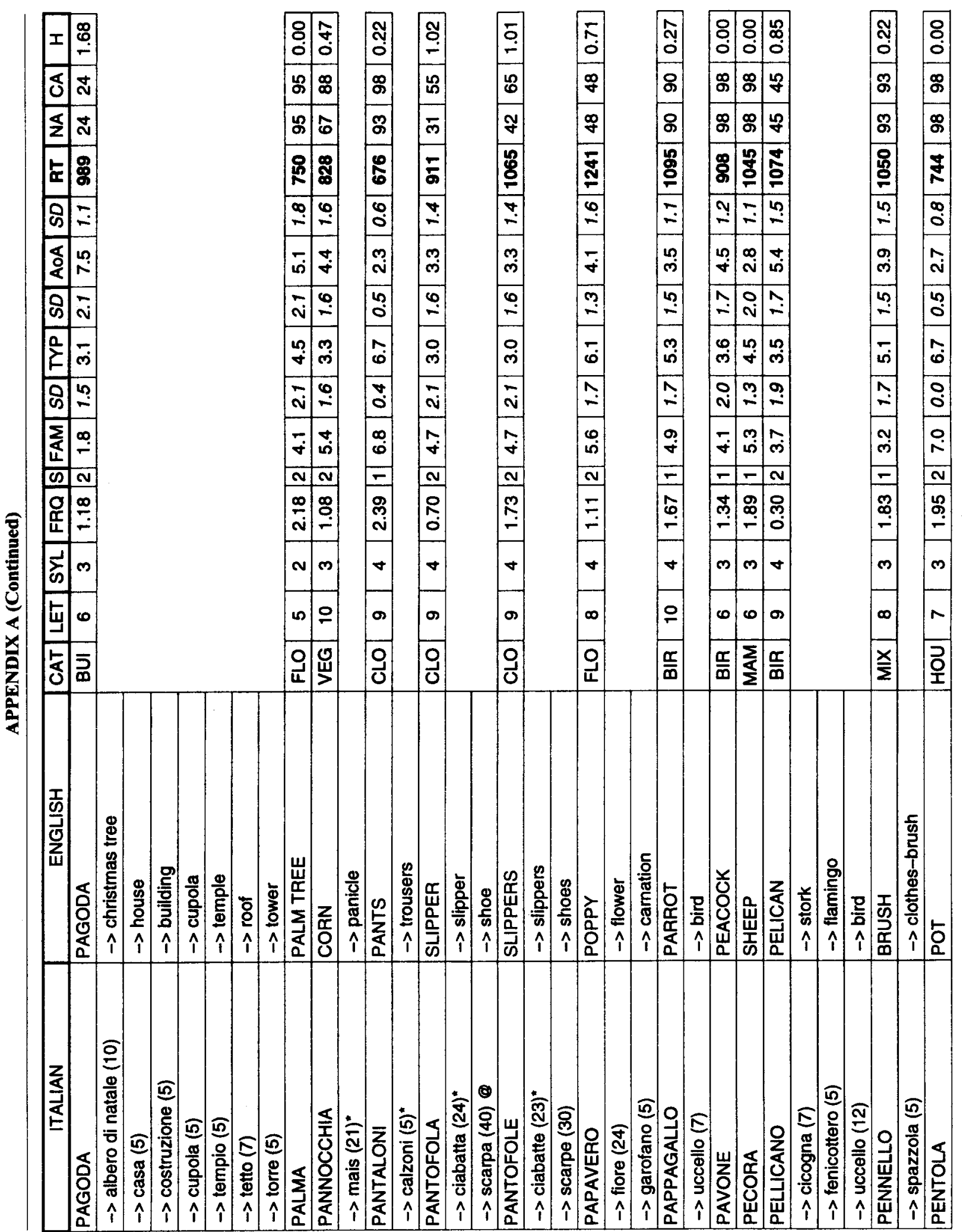




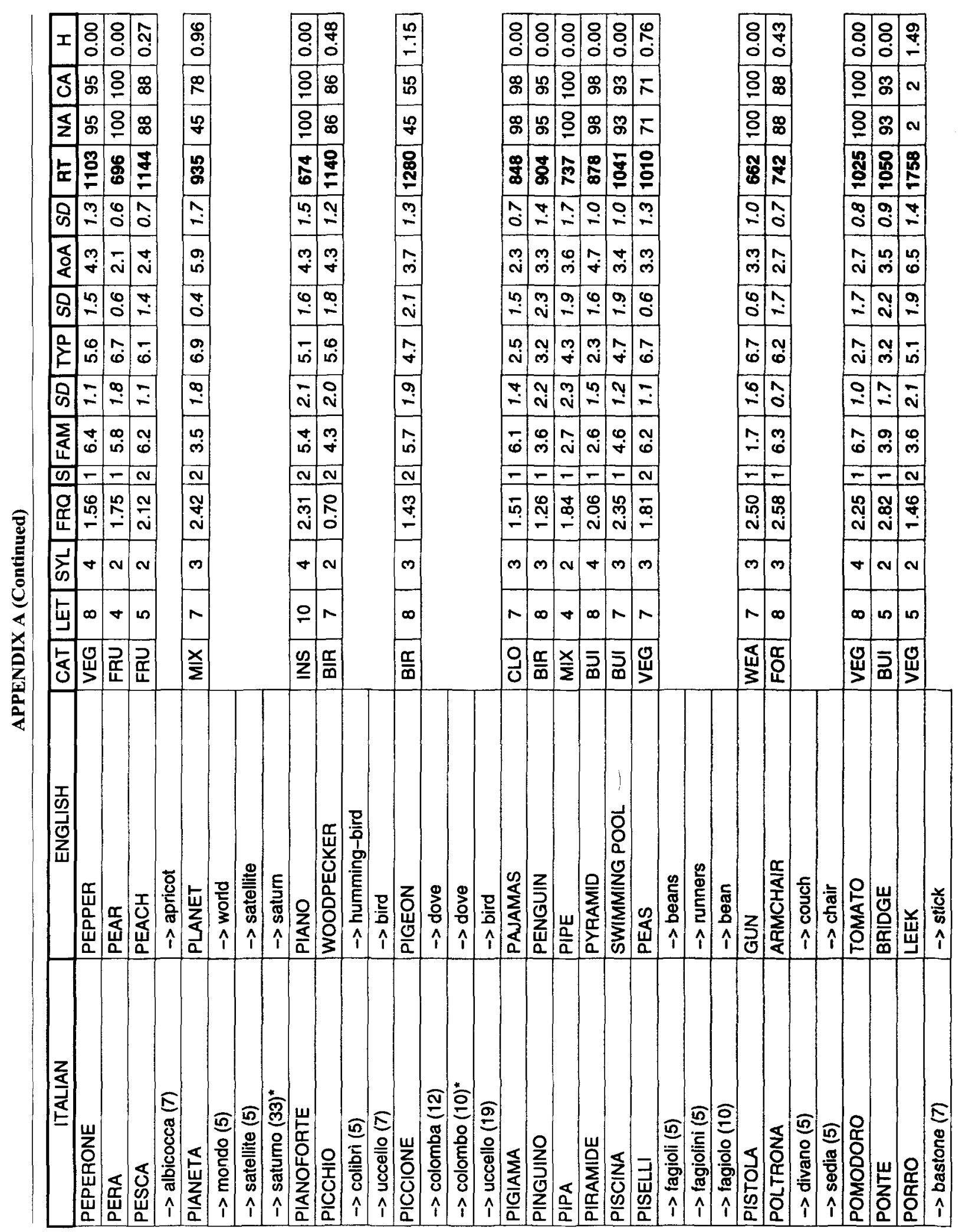




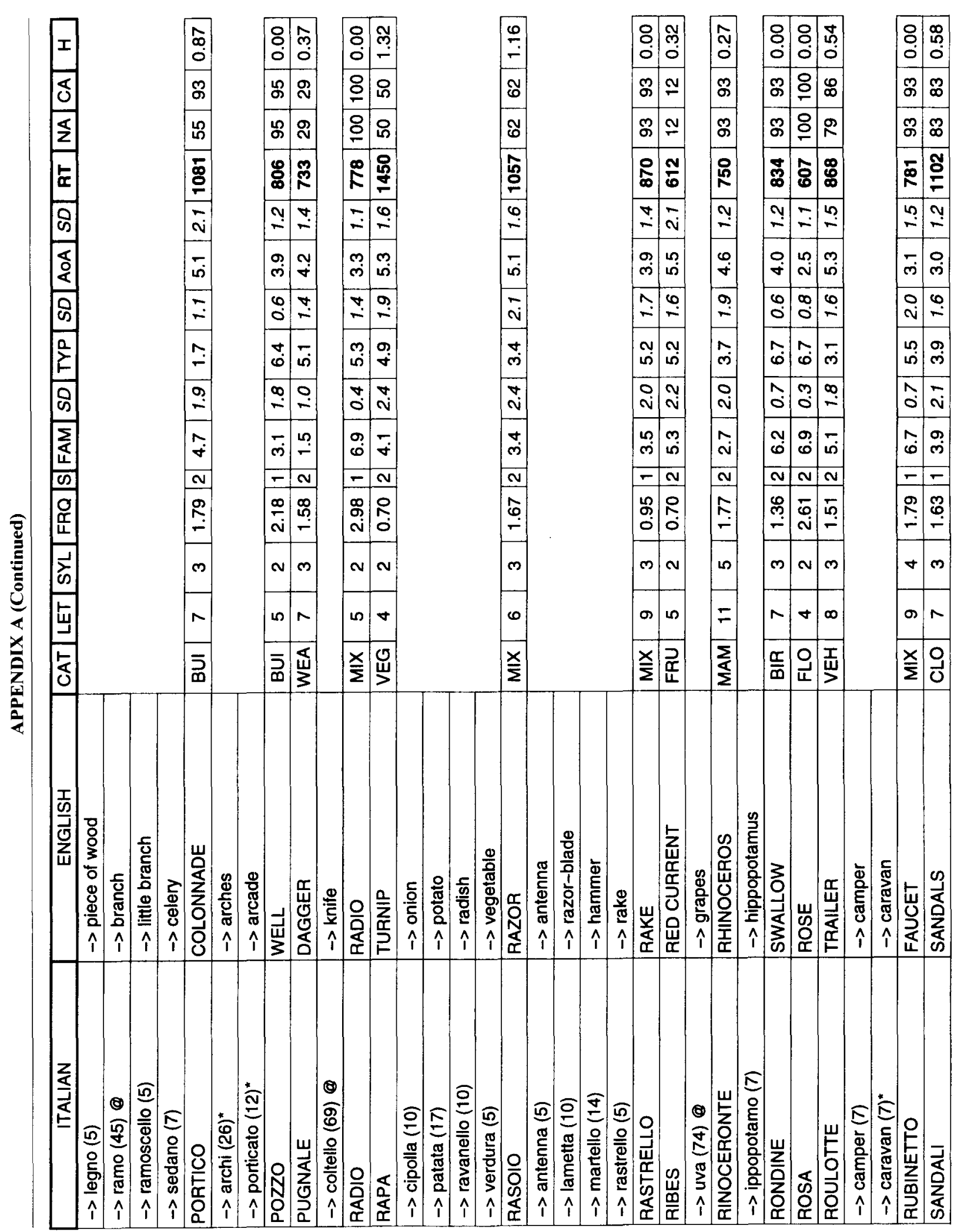




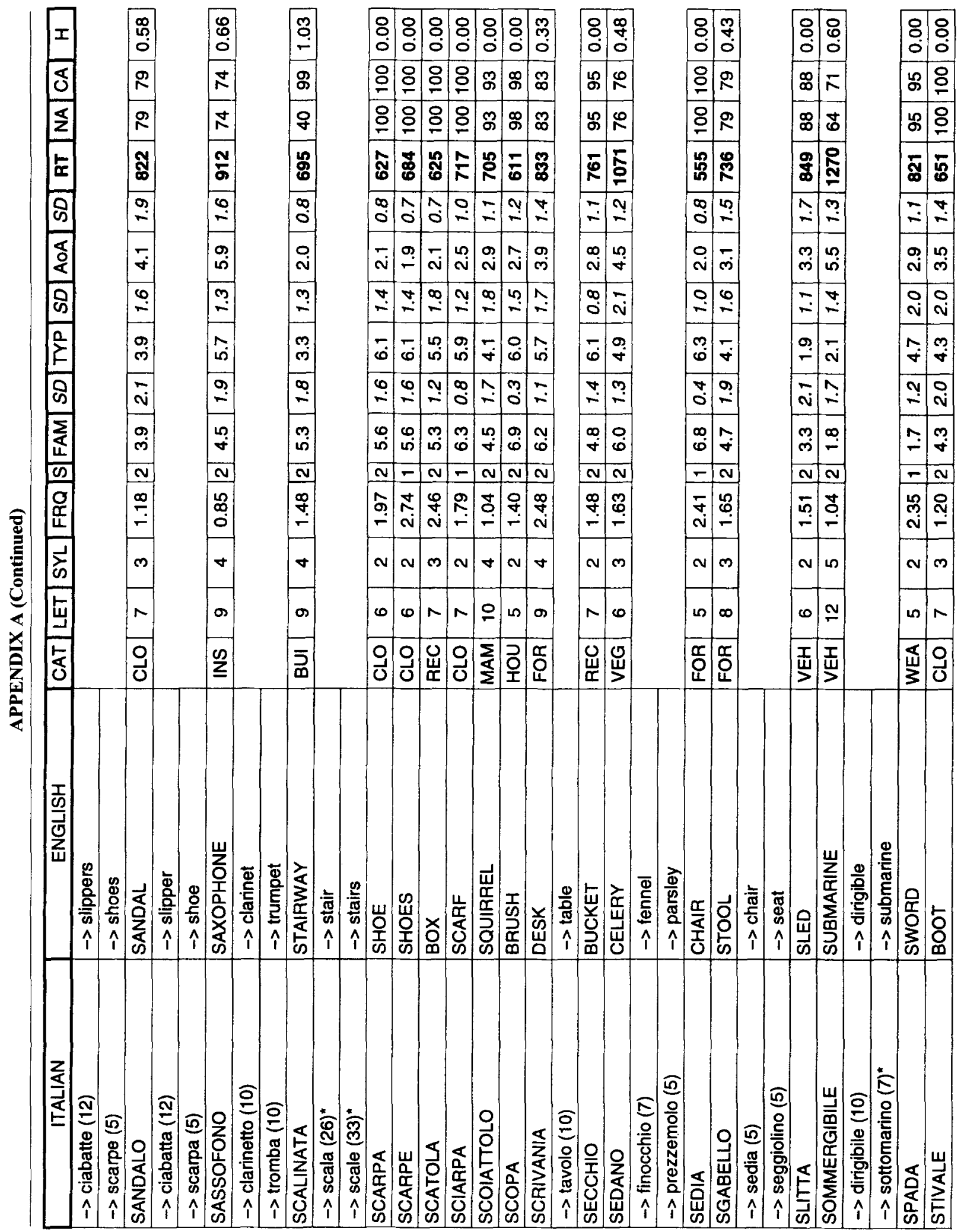




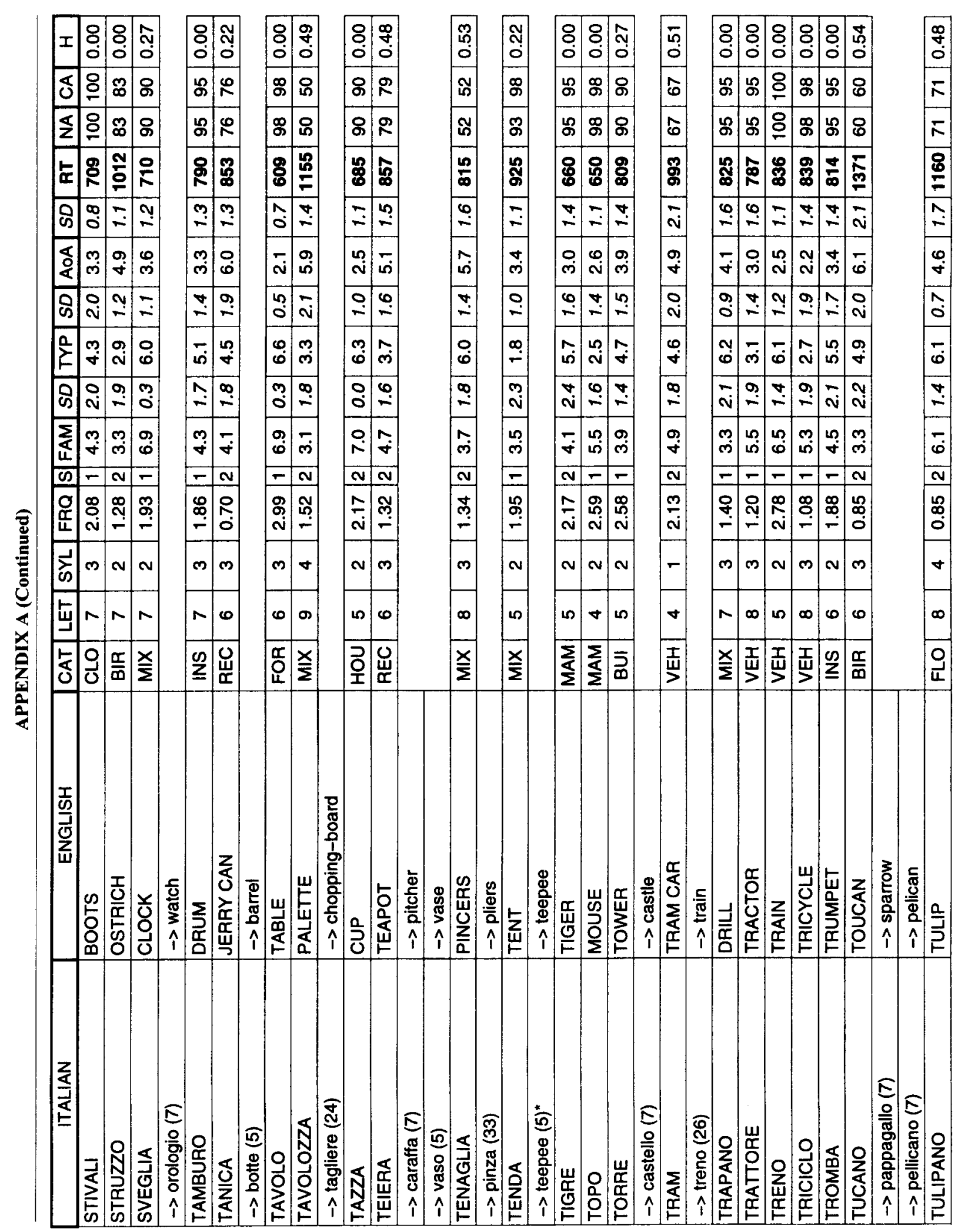




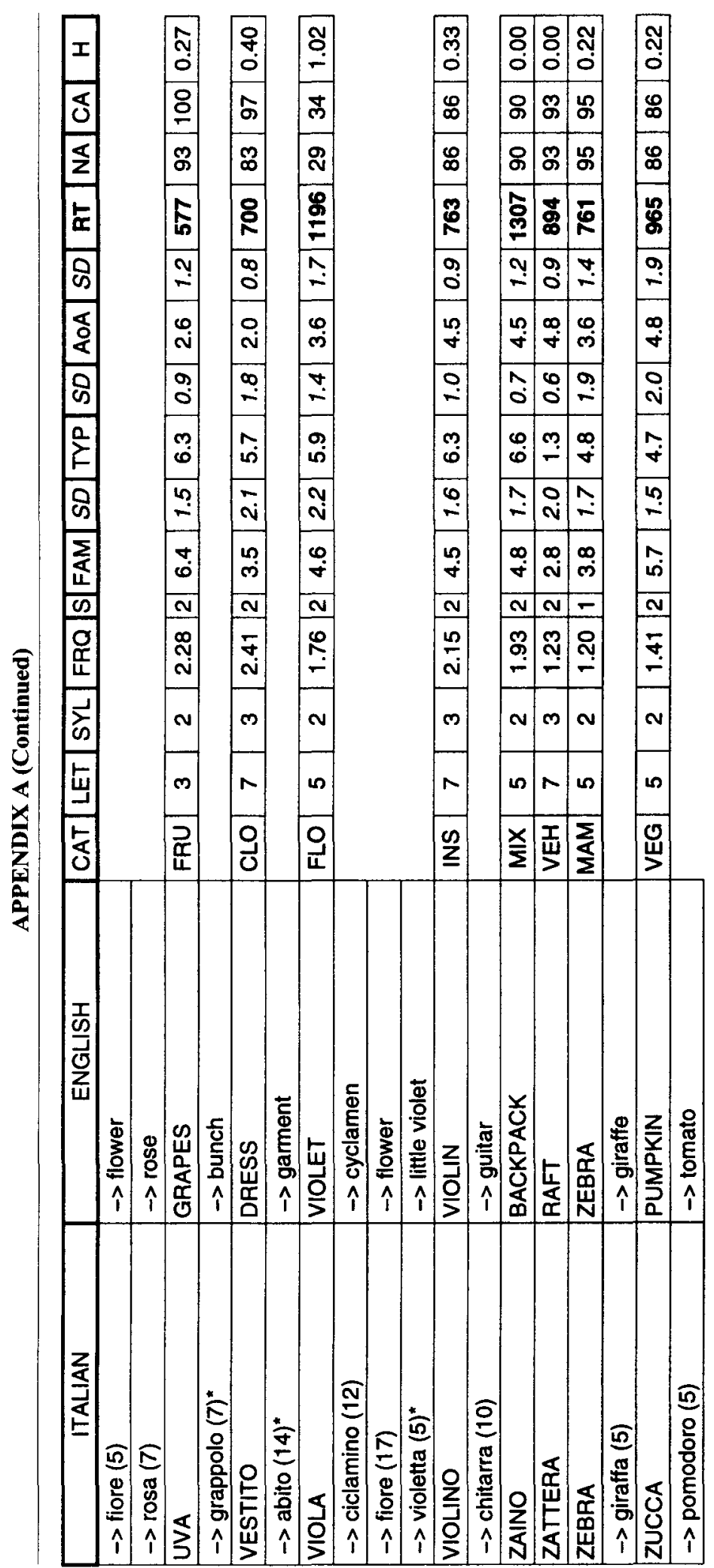


ஜூ 畜

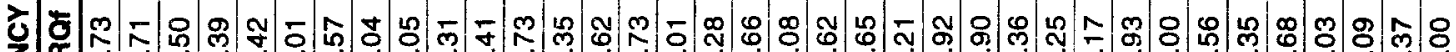
m

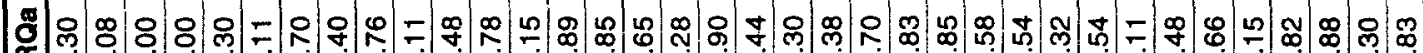

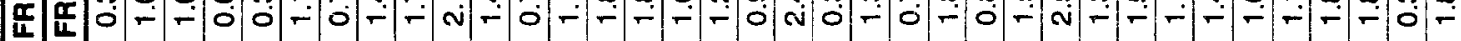
융ำ

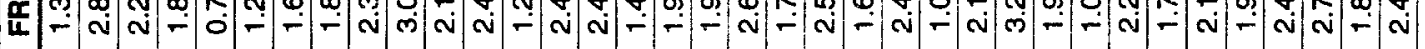

๓

*

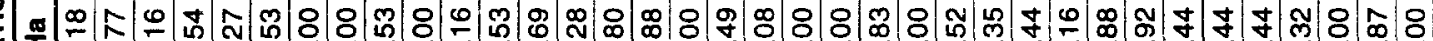

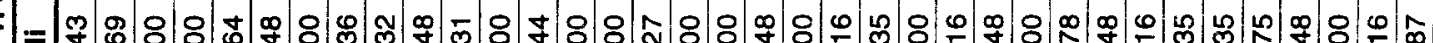

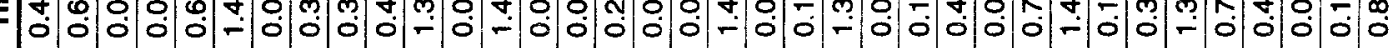

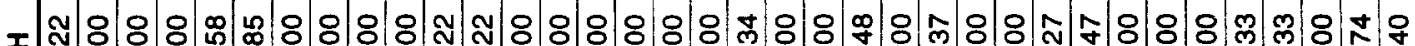

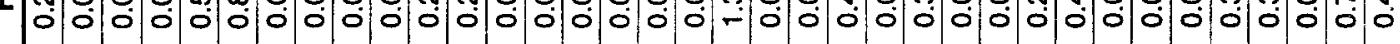

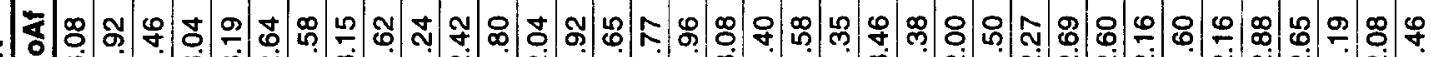

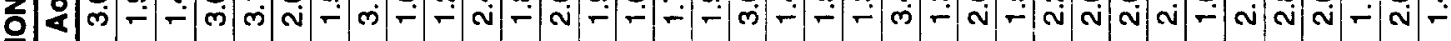

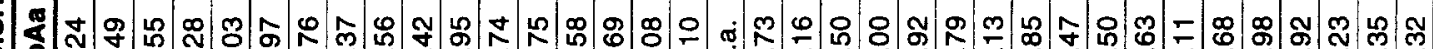

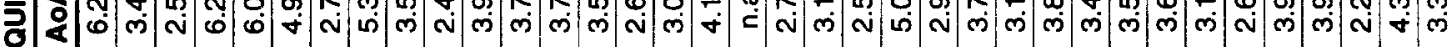

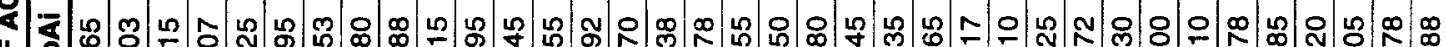
Uँ

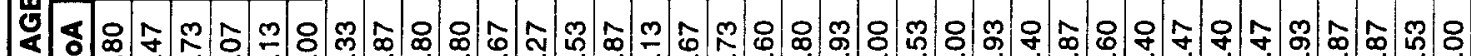
டे

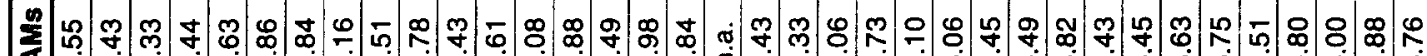

L्र

: ஜ

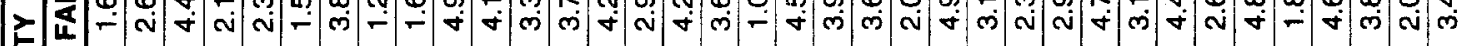

ㅁำ

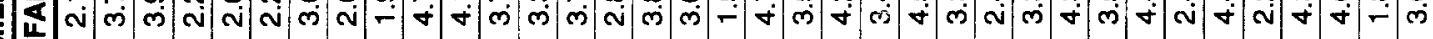

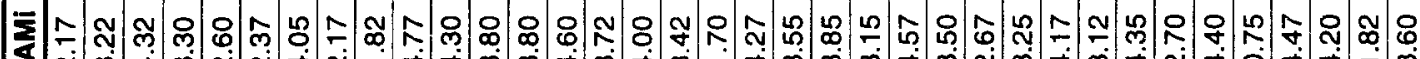

Lิ

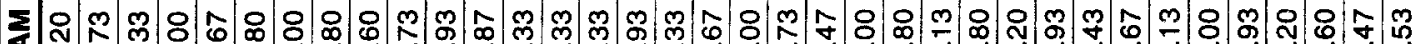

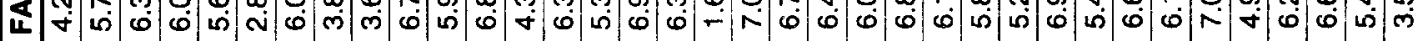




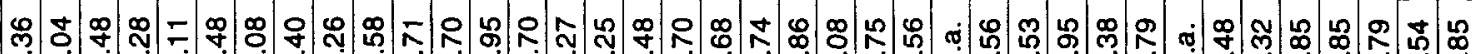

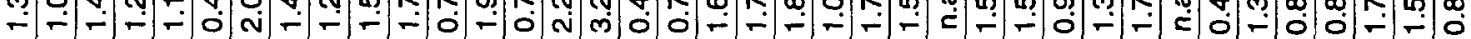

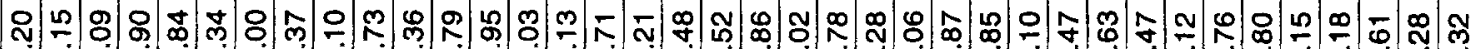

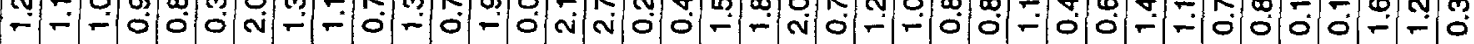

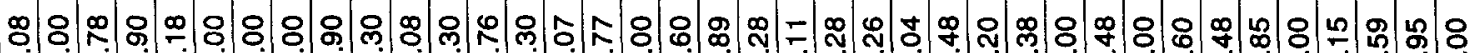

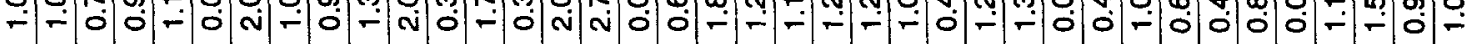

ஊ

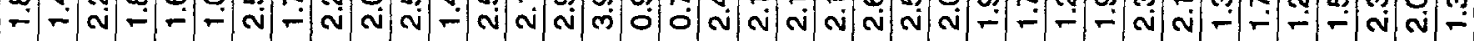

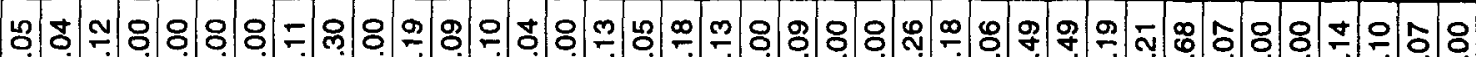

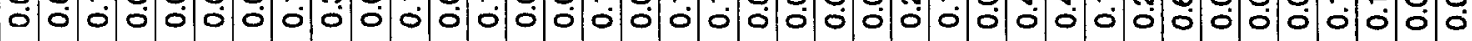

8 눈 8 8 8 윤 ○|c

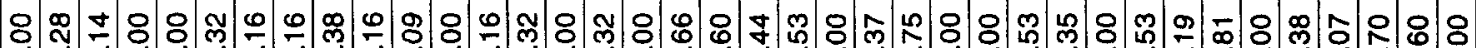

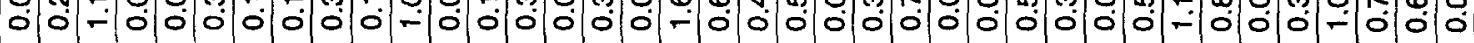

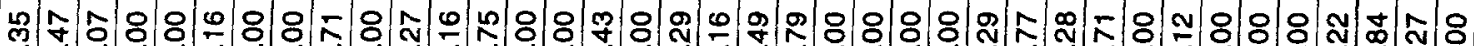

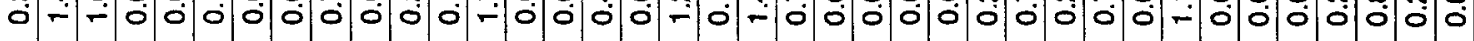

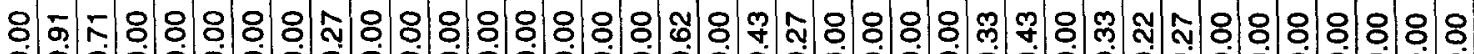

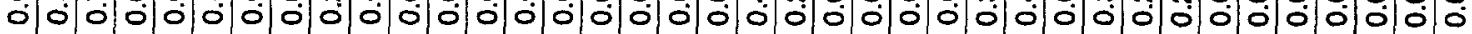

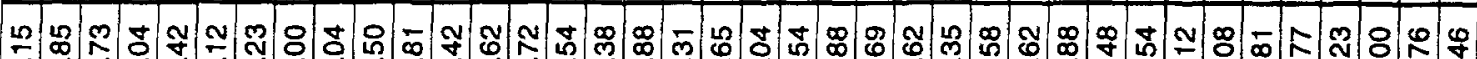

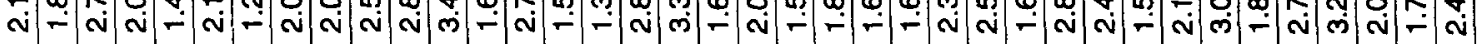

సิ இ: ナे N

ஜ

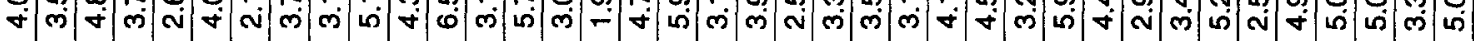

M

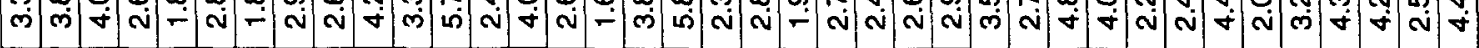

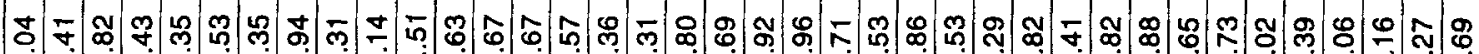

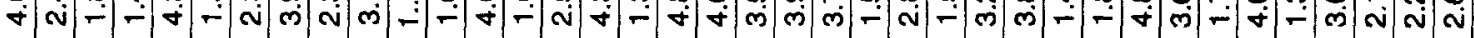

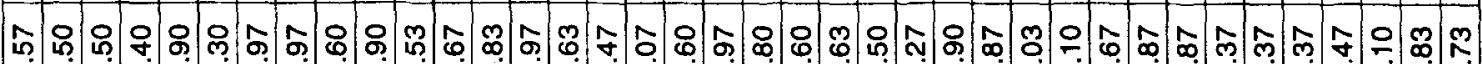

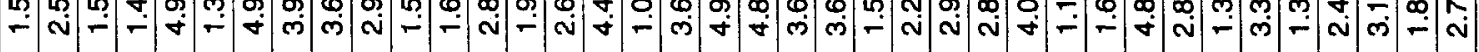

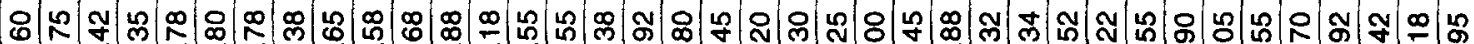

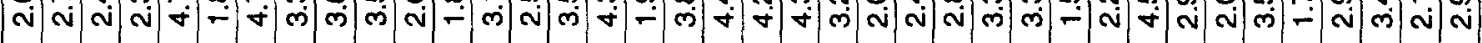

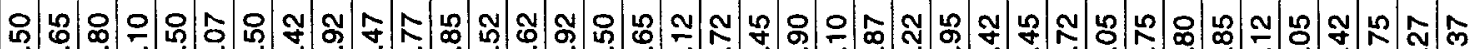

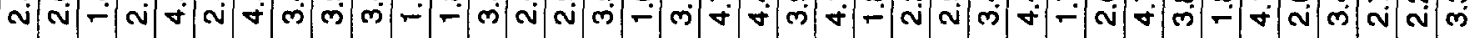

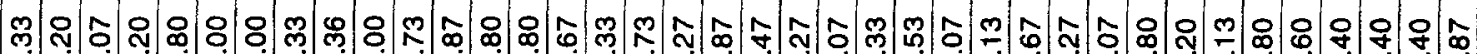

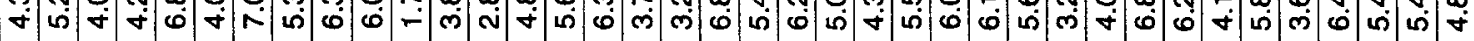

㲅

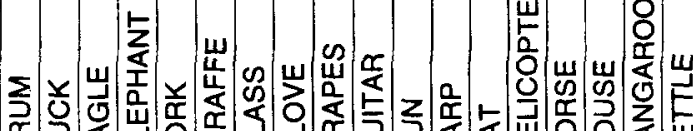

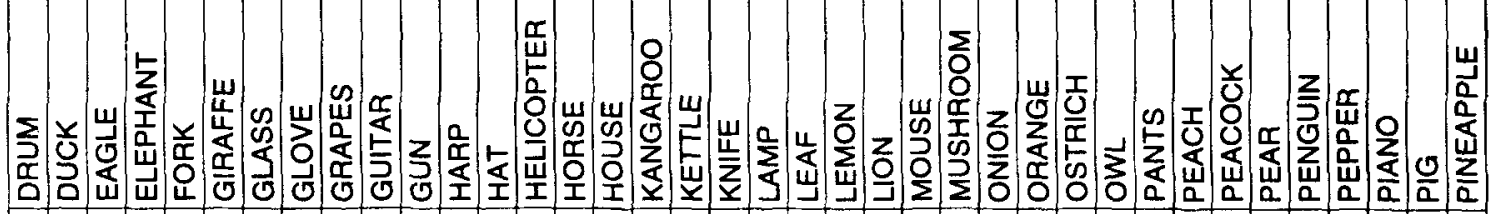

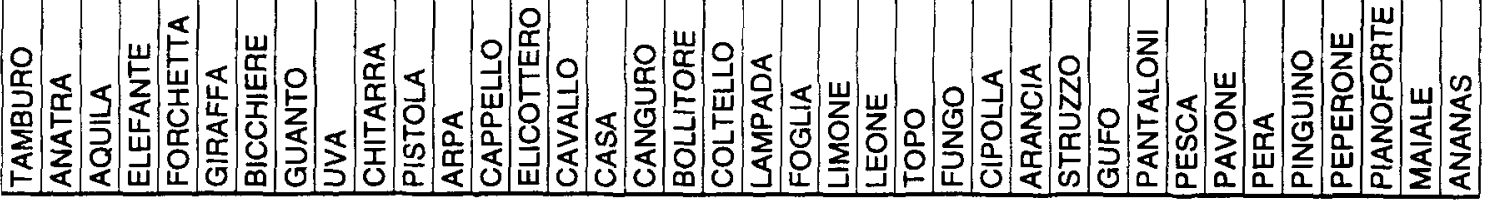


ㅇำ:

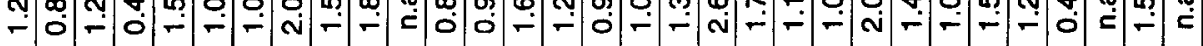
సิ సิ ్ㅣㅇㅛ

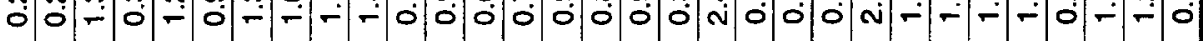

స్ \& - $0-00-0-0000000$ N $000-00-0$ N 00

宅

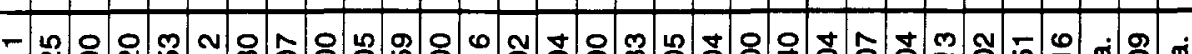
二

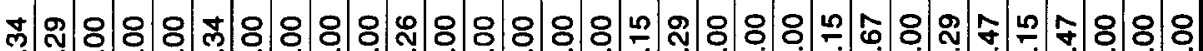

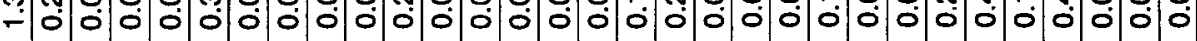
이느

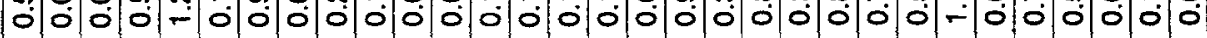

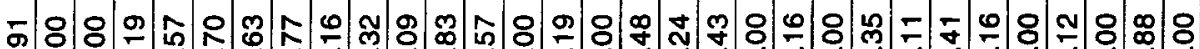

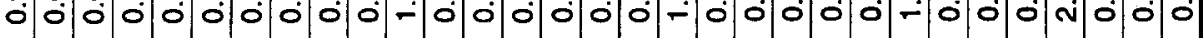

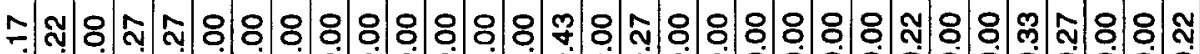

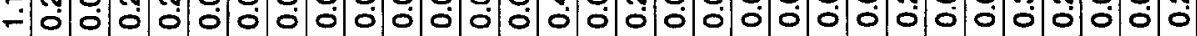

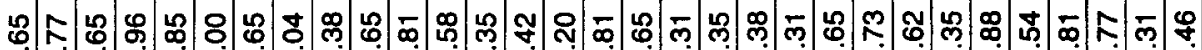
ஸ่ N่ N่

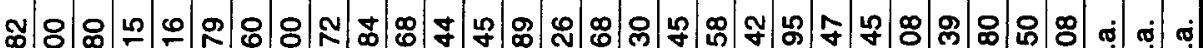
+ं

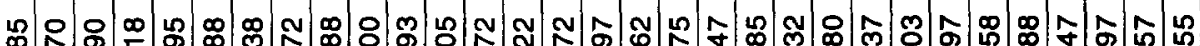
+

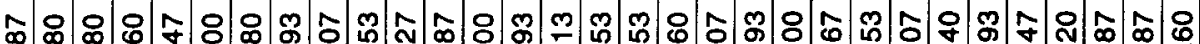

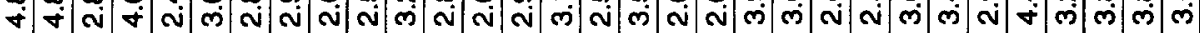

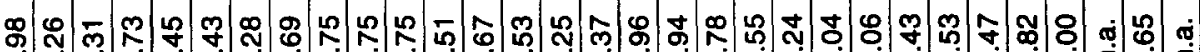
ஸे స่

దิ

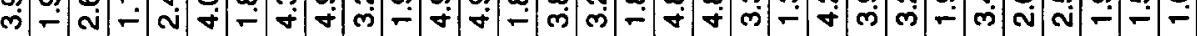

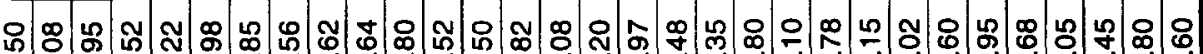
लं ल) N

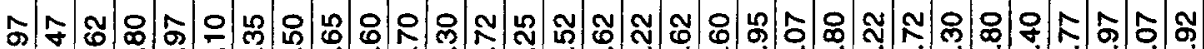
๓ं N N

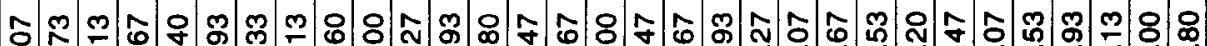

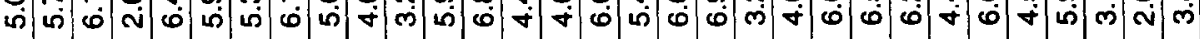

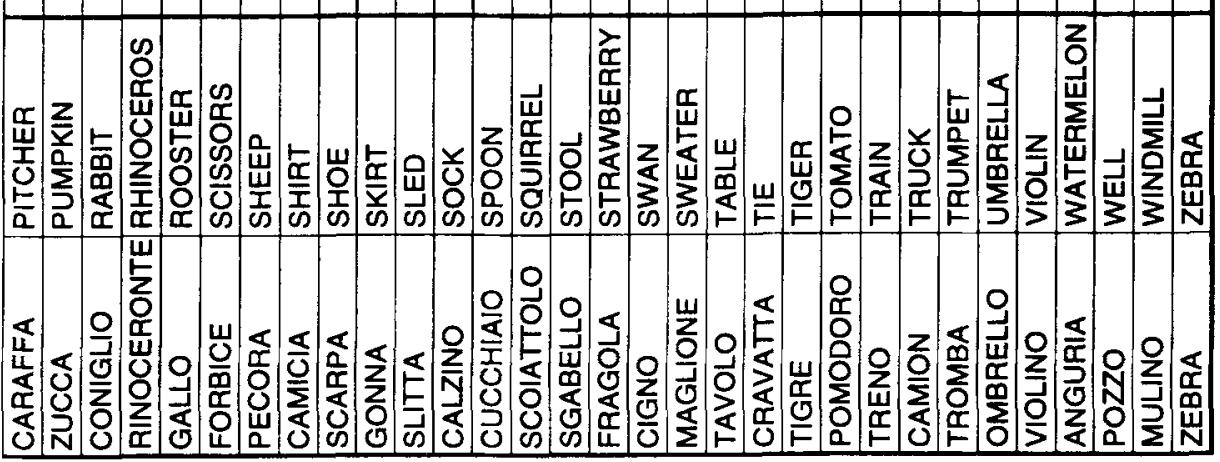

